\title{
Asymmetric nexus between technological innovation and environmental degradation in Sweden: an aggregated and disaggregated analysis
}

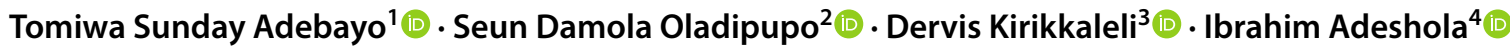

Received: 11 August 2021 / Accepted: 2 December 2021 / Published online: 22 January 2022

(C) The Author(s), under exclusive licence to Springer-Verlag GmbH Germany, part of Springer Nature 2021

\begin{abstract}
The number of studies on the relationship between technological innovation and $\mathrm{CO}_{2}$ emissions has gradually increased in recent years, although there is no clear agreement in the literature. Previous research has revealed both positive and negative consequences of technological innovation on the environment. Moreover, most researchers have used linear approaches to explore this connection, which can result in spurious outcomes when nonlinearities exist in the data. According to this background, this research utilizes asymmetric ARDL and spectral causality approaches to assess the asymmetric connection between technological innovation and $\mathrm{CO}_{2}$ emissions in Sweden utilizing data from 1980 to 2018. In addition, the disaggregated asymmetric effects of technological innovation (patent resident and patent nonresident) on $\mathrm{CO}_{2}$ are also captured in this study. The Nonlinear Autoregressive Distributed lag (NARDL) results showed that positive (negative) shocks in economic growth enhance environmental quality in Sweden. Furthermore, a positive (negative) shock in technological innovation causes a decrease (increase) in $\mathrm{CO}_{2}$. Similarly, a positive (negative) shock in patent nonresident and residents leads to a decrease (increase) in $\mathrm{CO}_{2}$ emissions in Sweden. The outcomes from the spectral causality revealed that in the medium and long term, aggregate and disaggregate technological innovation can predict $\mathrm{CO}_{2}$ emissions in $\mathrm{Sweden}$. This study has significant policy implications for policymakers and the government in Sweden. Based on these findings, the study suggests that the government of Sweden should investment in technological innovation since it plays a vital role in curbing environmental degradation.
\end{abstract}

Keywords $\mathrm{CO}_{2}$ emissions $\cdot$ Economic growth $\cdot$ Globalization $\cdot$ Technological innovation $\cdot$ Sweden

\section{Introduction}

Green growth will help to achieve the aims of the Paris Climate Conference (COP21). This will necessitate a reduction in carbon emissions $\left(\mathrm{CO}_{2}\right)$. These emissions are seen as a result of increased economic activity, which has caused concern for policymakers (Fareed et al. 2021; Li, Zhang, Zhang, $\mathrm{Wu}$, and Shi et al. 2021). $\mathrm{CO}_{2}$ emissions are renowned for their influence on environmental deterioration in the form of pollution, despite the fact that various other forms of emissions also exist. Globalization (GLO), economic growth (GDP), renewable energy consumption (REC), technological innovation (TI), financial development (FD), and human capital (HC) have all been linked with $\mathrm{CO}_{2}$ emissions (Ahmed and Le 2021; Alola et al. 2021; Bekun et al. 2021; Li et al. 2021a, b, c; Li, Zhang, Zhang, Wu, and Zhu et al. 2021c; Lin et al. 2021; Miao et al. 2018; Ozturk and Acaravci 2016). In this regard, it is crucial to acknowledge 
the climate change problem; otherwise, the associated risks and hazards, which are projected to rise in future years, will have devastating implications for human health and safety.

Technological innovation (TI) plays a vital role in mitigating $\mathrm{CO}_{2}$ whilst also helping to save energy. Additionally, technological innovation plays a crucial role in the efficient usage of both renewable and conventional energy sources. Moreover, technological innovation also improves the capacity of renewable energy, therefore increasing the total renewable energy supply to satisfy the future demand for energy. The role of technological innovation in reducing $\mathrm{CO}_{2}$ has been demonstrated in existing studies, although it has never been given suitable attention. Few studies have assessed the association between technological innovation and $\mathrm{CO}_{2}$ emissions. For instance, Ko et al. (2021) scrutinized the impact of technological innovation on $\mathrm{CO}_{2}$ emissions and the outcomes from the study revealed a negative connection between technological innovation and $\mathrm{CO}_{2}$ emissions. Likewise, the study of (Kirikkaleli and Adebayo 2021) utilizing the global economy found that technological innovation can aid in mitigating $\mathrm{CO}_{2}$. Moreover, Cheng et al. (2021) assessed the association between technological innovation and $\mathrm{CO}_{2}$ emissions in 5 OECD countries and the outcomes showed that an upsurge in technological innovation mitigates $\mathrm{CO}_{2}$ in the selected OECD nations. On the other hand, some studies have established that technological innovation contributes to the degradation of the environment. For instance, the study of (Adebayo and Kirikkaleli. 2021) established a positive connection between technological innovation and $\mathrm{CO}_{2}$ emissions in Japan. Likewise, the study by Su et al. $(2021 \mathrm{a}, \mathrm{b})$ on the interconnection between technological innovation and $\mathrm{CO}_{2}$ emissions in the BRICS economies revealed that an upsurge in technological innovation stimulates $\mathrm{CO}_{2}$ in the BRICS nations. Similarly, the study of Dauda et al. (2021) in selected Africa economies established a positive interrelation between technological innovation and $\mathrm{CO}_{2}$ emissions. Although the existing literature has found mixed evidence of the role of technological on $\mathrm{CO}_{2}$ emissions, its importance for $\mathrm{CO}_{2}$ emissions cannot be ignored.

Globalization is a universal phenomenon that has a substantial impact on people's political, economic, and social lives. It reduces/removes cross-border barriers, facilitates modern technological exchanges, and boosts capital inflows and investment (Leal and Marques. 2021). While globalization benefits the economy, it also has an influence on the environment (Rahman. 2020; Usman et al. 2020; Yameogo et al. 2021). The influence of globalization on $\mathrm{CO}_{2}$ emissions is theoretically ambiguous. As a result, there is a theoretical debate over the connection between globalization and $\mathrm{CO}_{2}$. For example, advocates of the pollution-haven hypothesis argue that, as a result of industrialized nations' strict environmental government regulations, emerging economies have become hosts to environmentally damaging businesses from industrialized nations. The enormous costs of environmental damage are imposed by the rigorous environmental regulatory systems of industrialized countries. These polluting companies migrate to emerging nations with lax environmental regulations in order to remain competitive (Koondhar et al. 2021; Shahbaz et al. 2018). The pollution-halo hypothesis, on the other hand, contends that globalization decreases $\mathrm{CO}_{2}$ by ensuring the transmission and dissemination of ecologically efficient technology, knowledge, and conventional environmental management practices in host nations (Ahmed and Le. 2021; Rahman. 2020; Usman et al. 2020). Likewise, Kirikkaleli et al. (2021) suggested that globalization can assist nations to reduce $\mathrm{CO}_{2}$ by allowing them to adjust the mix of their consumption and production as they become richer. The outcomes are contradictory and ambiguous due to the competing theoretical arguments (Koengkan et al. 2020; Leal and Marques. 2021; Rahman. 2020), while others have reported that globalization impacts $\mathrm{CO}_{2}$ emissions positively (Koengkan et al. 2020; Usman et al. 2020; Yameogo et al. 2021). In addition, some studies have found an insignificant interconnection between globalization and $\mathrm{CO}_{2}$ emissions (Haseeb et al. 2018; Le and Ozturk. 2020; Xu et al. 2018).

Based on the previous discussion, the current study has the following objectives. The first objective is to assess the economic growth role in mitigating $\mathrm{CO}_{2}$ emissions. Secondly, the study scrutinizes the effect of globalization on $\mathrm{CO}_{2}$. Thirdly, the paper explores the effect of aggregated and disaggregated technological innovation on $\mathrm{CO}_{2}$ in Sweden.

Why Sweden? Sweden is an advanced economy whose GDP per capita and GDP amounted to US\$51,615.02 and US\$530.9 billion in 2019 (World Bank. 2021). Moreover, even though few nations utilize more energy per capita than Sweden, Swedish carbon emissions are relatively modest when compared to those of other nations. Sweden's low emission rate is due to the fact that nuclear and hydroelectric power account for roughly $80 \%$ of the country's electricity generation. In 2012, the nation had already achieved the government's 50\% objective for 2020 (BP. 2021). By 2040, the goal for the power industry is to produce $100 \%$ renewable electricity. Sweden is a global pioneer in decarbonization, with the objective of achieving a 59\% reduction in GHGs emissions by 2030 compared to 2005 , and a net-zero carbon economy by 2045 (IEA. 2021). Sweden was the first nation to implement carbon pricing, and it now has the globe's highest carbon prices, which has shown to be beneficial in promoting decarbonization. Moreover, as revealed by Figs. 1 and 2, it illustrates the trend of total energy supply and lowcarbon electricity generation by source from 1990 to 2019 . In terms of innovation, Sweden has excelled significantly in the global context. For instance, in 2020, Sweden was 
Fig. 1 Trend of total energy supply by source in Sweden

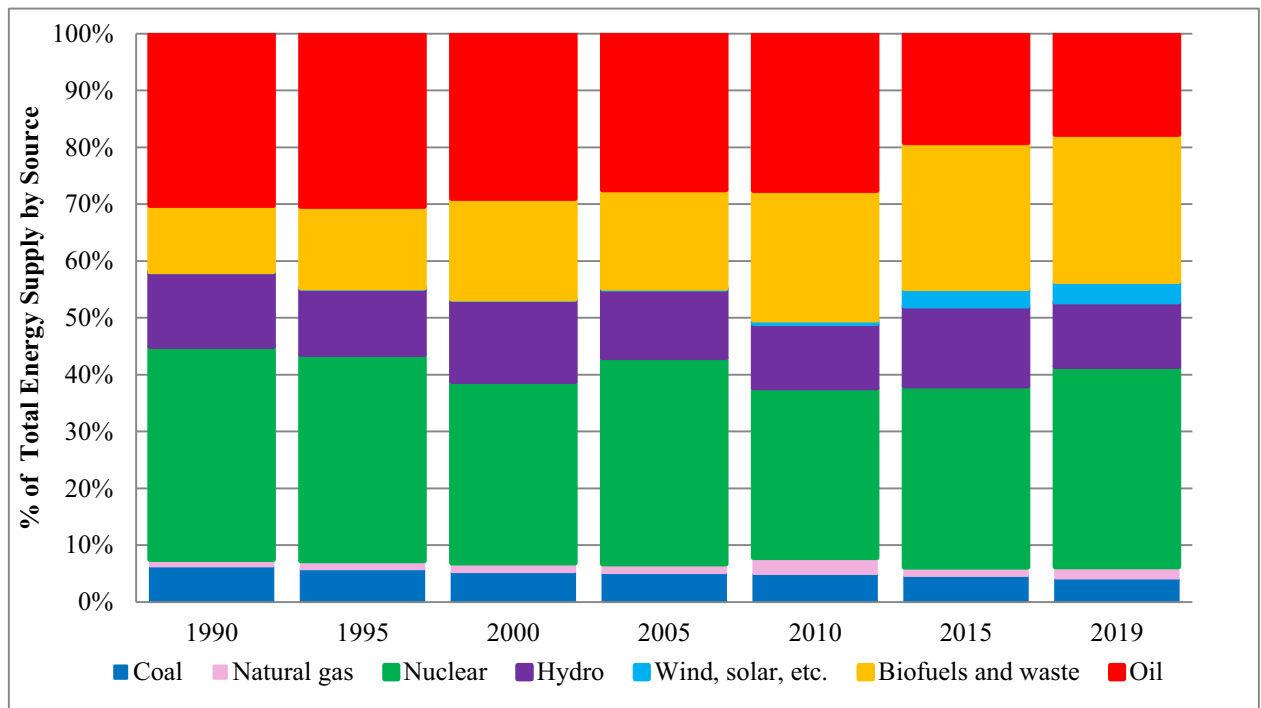

Fig. 2 Trend of low-carbon electricity generation by source in Sweden

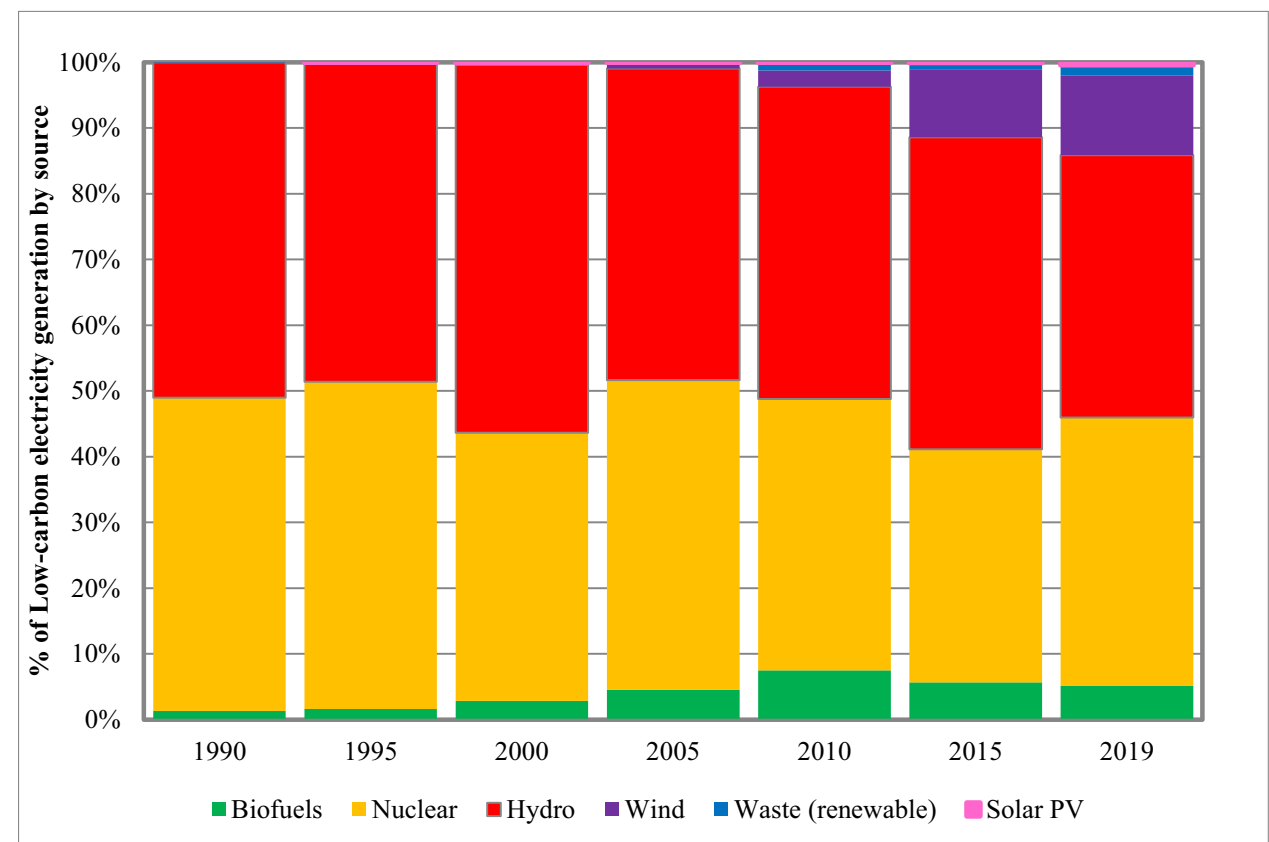

ranked 2 nd globally as the most innovative country according to the Global Innovation Index.

Considering these interesting facts about Sweden, it is reasonable to expect that Sweden will require an inclusive policy framework in order to make progress towards achieving the SDG goals by 2030. In pursuit of this goal, the current study examines the asymmetric, aggregated, and disaggregated influence of technological innovation on $\mathrm{CO}_{2}$ emissions in Sweden and takes into account the influence of globalization between 1980 and 2018. In order to achieve this policy-level objective, it is necessary to understand that the model parameters might not have the same impacts on the target policy variable whenever they encounter an external shock. On the other hand, it is possible that those shocks will appear in certain time differentials. Hence, in order to design a robust policy framework, the methodological adaptation needs to complement these aspects of policy formulation. In this context, the nonlinear autoregressive distributed lag (NARDL) method developed by (Shin et al. 2014) is employed in this study. This method is capable of capturing the differential impacts of the model parameters on the target policy variable in cases of positive and negative shocks. In view of this, this method is capable of complementing the policy-level contributions of the study, and thereby, indicating the analytical contribution of the study.

The remaining sections of this research are compiled as follows: Sect. 2 presents a synopsis of related studies. Section 3 presents the theoretical underpinning. The data 
and methods are presented in Sect. 4. Section 5 portrays the findings and discussion and the conclusion is presented in Sect. 6.

\section{Empirical review}

Numerous studies have been conducted on the association between $\mathrm{CO}_{2}$ emissions $\left(\mathrm{CO}_{2}\right)$ and technological innovation (TI), globalization (GLO), and economic growth (GDP); however, missed outcomes have been generated. Therefore, the following subsection presents a summary of studies on these issues.

\section{$\mathrm{CO}_{2}$ emissions and economic growth relationship}

Using five EU nations, Balsalobre-Lorente et al. 2018) scrutinized the emission-growth nexus utilizing data from the period between 1985 and 2016. The authors applied panel techniques to investigate this association and their outcomes confirmed the $\mathrm{N}$-shaped interconnection between $\mathrm{CO}_{2}$ and economic growth in the five EU nations. Likewise, Bakhsh et al. 2017) examined the impact of economic growth on $\mathrm{CO}_{2}$ emissions in Pakistan for the period 1980-2014. Utilizing the 3SLS method, the outcomes of the study showed that an upsurge in GDP triggers $\mathrm{CO}_{2}$ in Pakistan. Moreover, using data from 2001 to 2017 and applying SUR and GMM in the MENA economies, Muhammad. 2019) scrutinized the impact of economic growth on $\mathrm{CO}_{2}$ emissions. The outcomes of this study demonstrated a positive association between economic growth and $\mathrm{CO}_{2}$ emissions in the MENA economies. Furthermore, the study of Munir et al. 2020) on the emissions-growth interconnection in the ASEAN-5 countries using recent panel techniques revealed a positive association between economic growth and $\mathrm{CO}_{2}$ emissions in these countries. In addition, evidence was found of a oneway causal interrelation from economic growth to $\mathrm{CO}_{2}$. Furthermore, Hanif et al. 2019) assessed the connection between economic growth and $\mathrm{CO}_{2}$ emissions in emerging Asian economies utilizing data from 1990 to 2013. The study applied the ARDL and their outcomes showed a positive emissions-growth interconnection in the emerging Asian economies. The study of Mikayilov et al. 2018) in Azerbaijan on the growth-emission association utilizing DOLS, FMOLS, and CCR between 1992 and 2013 found a positive linkage between growth and emissions. Furthermore, the EKC hypothesis was also validated for the case of Azerbaijan. In the USA, Salari et al. 2021) examined the growthemission relationship utilizing data from 1997 to 2016 and their outcomes revealed a positive growth-emission interrelation. Furthermore, the EKC hypothesis was confirmed in the USA. Using the ARDL and TY causality approaches and data from 1975 to 2017, Udemba et al. 2021b) assessed the influence of GDP on $\mathrm{CO}_{2}$ and their outcomes showed a positive $\mathrm{CO}_{2}$-GDP connection. Likewise, in China, Liu et al. (2021) scrutinized the $\mathrm{CO}_{2}$-GDP interconnection utilizing data from 1965 to 2016 and their outcomes showed a positive $\mathrm{CO}_{2}$-GDP connection. Furthermore, a two-way causality was confirmed from GDP to $\mathrm{CO}_{2}$. Similarly, the study of Gao and Zhang. 2021) in 13 Asian developing countries using FMOLS disclosed that economic growth triggers $\mathrm{CO}_{2}$ emissions and a one-way causality was found running from economic growth to $\mathrm{CO}_{2}$. Moreover, the study of Shan et al. 2021) on the top seven fiscally decentralized OECD nations on the growth-emission interrelation using CS-ARDL and AMG techniques and data from 1990 to 2018 found a positive growth-emission interrelation.

\section{$\mathrm{CO}_{2}$ emissions and technological innovation relationship}

Technological innovation is essential for reducing emissions and promoting energy conservation. Furthermore, TI is required for the most efficient use of both renewable and traditional energy sources. Dauda et al. 2021) scrutinized the impact of technological innovation on $\mathrm{CO}_{2}$ emission association in selected Africa nations utilizing data from 1990 to 2018. The outcomes from the study revealed a negative connection between technological innovation and $\mathrm{CO}_{2}$ emissions and a one-way causality was discovered running from technological innovation to $\mathrm{CO}_{2}$ emissions, suggesting that technological innovation can predict $\mathrm{CO}_{2}$. Likewise, the study of Kirikkaleli and Adebayo. 2020) utilizing the global economy and data from 1980 to 2018 unveiled that technological innovation mitigates $\mathrm{CO}_{2}$. In addition, evidence was found of a causality running from technological innovation to $\mathrm{CO}_{2}$ emissions Zhao et al. 2021) scrutinized the interrelation between technological innovation and $\mathrm{CO}_{2}$ emissions in 62 countries from 2003 to 2018. The study applied the panel techniques and the outcomes revealed a positive association between technological innovation and $\mathrm{CO}_{2}$ emissions in 62 selected countries. Using panel quantile regression, Chen et al. 2019) assessed the impact of technological innovation on $\mathrm{CO}_{2}$ emissions in 5 OECD countries from 1996 to 2015 . The study outcomes revealed that an upsurge in technological innovation mitigates $\mathrm{CO}_{2}$ in the selected OECD nations. Using wavelet tools, Adebayo and Kirikkaleli. 2021) investigated the connection technological innovation and $\mathrm{CO}_{2}$ emissions in Japan using a dataset between 1990Q1 and 2015Q4. The study outcomes showed positive co-movement between technological innovation and $\mathrm{CO}_{2}$ emissions in the medium and long term, which implies that a rise in technological innovation contributes to the degradation of the environment. Similarly, Chen and Lee. 2020) explored the linkage technological innovation and $\mathrm{CO}_{2}$ emissions in China using a dataset from 1990 to 2018 employing the novel QARDL approach. The outcomes revealed a 
negative connection between technological innovation and $\mathrm{CO}_{2}$ emissions in the majority of the quantiles. Likewise, the study by Su et al. 2021a, b) on the interconnection between technological innovation and $\mathrm{CO}_{2}$ emissions in the BRICS economies unveiled that an upsurge in technological innovation stimulates $\mathrm{CO}_{2}$ in these nations. Dauda et al. 2021) explored the interaction between technological innovation and $\mathrm{CO}_{2}$ emissions in selected countries in Africa using data from 1990 to 2016 and the findings from the GMM showed that technological innovation decreases the quality of the environment. Likewise, the study of Ko et al. 2021) in South Africa on the influence of technological innovation on $\mathrm{CO}_{2}$ emissions also disclosed a positive association between $\mathrm{CO}_{2}$ emissions and technological innovation. Using East-Asia and Pacific countries as a case study, the study of Chaudhry et al. 2021) found that an increase in technological innovation mitigates $\mathrm{CO}_{2}$. Moreover, the study of Ali et al. 2020) using dynamic common correlated effects in OIC countries disclosed that technological innovation aids in mitigating $\mathrm{CO}_{2}$ emissions. Lastly, the research of Ali et al. 2021) in OIC countries showed that a reduction in $\mathrm{CO}_{2}$ was caused by a $1 \%$ increase in technological innovation.

Based on the reviewed literature, it is clear that there are mixed findings regarding the impact of technological innovation on $\mathrm{CO}_{2}$ emissions using time-series and panel analyses. Therefore, the current research differentiates itself by providing a robust analysis of the impact of technological innovation (patent resident and patent nonresident) on $\mathrm{CO}_{2}$ emissions in Sweden within the framework of advanced econometric methodologies including nonlinear autoregressive distributed lag (NARDL), Unit Root, BDS Test, and Spectral Granger Causality. Exploring the combination of these methodologies helps to exploit the novelty of the approaches, thereby providing robust estimates that support proactive policy directions.

\section{$\mathrm{CO}_{2}$ emissions and globalization relationship}

Through worldwide networks of industry, research and development, and capital flows, globalization promotes the dissemination of climate-friendly technology. On the other hand, the expansion of new technology via globalization will make climate action easier to monitor and more transparent. Over the years, numerous scholars have tried to report on the effects of globalization (GLO) on $\mathrm{CO}_{2}$ emissions $\left(\mathrm{CO}_{2}\right)$; nonetheless, their outcomes have generated mixed findings. For instance, Muhammad and Khan (2021) assessed the emission-globalization association in 31 developed and 155 developing economies between 1991 and 2018 utilizing the GMM approach and their outcomes revealed that in emerging nations, globalization reduces environmental quality, whereas in advanced nations, globalization enhances the quality of the environment. Likewise, the study of Rahman
(2020) used FMOLS and DOLS to investigate the emissionglobalization nexus in the top 10 electricity-consuming countries between 1971 and 2013 and found a negative interrelation between globalization and $\mathrm{CO}_{2}$ emissions. In addition, the panel causality revealed a one-way causation from globalization to $\mathrm{CO}_{2}$ implying that globalization can predict $\mathrm{CO}_{2}$ emissions in the top 10 electricity-consuming countries. Furthermore, utilizing the panel ARDL approach (Leal and Marques. 2021) explored the emission-globalization connection in 23 African countries between 1999 and 2017. Their outcomes showed that political and economic globalization enhance environmental quality. Moreover, in Latin American and Caribbean nations, evidence was found of a positive connection between globalization and $\mathrm{CO}_{2}$ emissions by the study of Koengkan et al. (2020) on the association between $\mathrm{CO}_{2}$ and globalization. Likewise, the study of Yameogo et al. (2021) on the emission-globalization association in sub-Saharan Africa from 2002 to 2017 found that the emission-globalization relationship was negative in SSA economies. Similarly, Usman et al. (2020) assessed the interrelation between globalization and $\mathrm{CO}_{2}$ emissions in Brazil utilizing a dataset from 1971 to 2014 . The investigators applied the DOLS and FMOLS approaches, and their outcomes showed that globalization impedes degradation of the environment. On the contrary, the study of He et al. (2021) on the interconnection between globalization and $\mathrm{CO}_{2}$ emissions in Mexico using a dataset from 1990 and 2018 and applying the novel gradual shift causality and ARDL approaches found that an upsurge in globalization contributes to $\mathrm{CO}_{2}$. In addition, a unidirectional causation from globalization to $\mathrm{CO}_{2}$ in the long and medium term was identified. Furthermore, in Turkey, the study of Kirikkaleli et al. (2021) utilizing the novel Dual Gap FMOLS and DOLS approaches between the period 1970 and 2018 discovered that globalization contributes to the degradation of the environment.

\section{Theoretical framework, data, and methodology}

\section{Theoretical framework}

The global economy has grown tremendously during the last four decades, including a substantial increase in energy use. Unfortunately, rapid economic growth and growing energy consumption have had negative environmental effects. Kraft and Kraft (1978) were the first to show a connection between energy use and economic progress. As stated by Sarkodie and Strezov (2019), achieving sustainable growth is difficult if environmental issues such as global warming and climate change continue to increase. Environmental economists including Panayotou (1997) and Grossman and 
Krueger (1991) used this approach to investigate the connection between environmental deterioration and economic expansion. According to them, economic growth occurs in three separate phases (scale, composite, and technique effects). The initial phase is known as the scale effect phase, while the turning point and the time after the turning point are recognized as the composite and technique effect stages, respectively. The scale impact phase is linked to emerging economies where nonrenewable sources of energy support economic growth. The environment will suffer in the early stages of growth until a specific threshold (the turning point) is achieved; growth will increase the degradation of the environment at this period. The composite and technique effect stages, on the other hand, are associated with developed nations such as Sweden, where technical innovation and services dominate the economy.

Technological innovation (TI) is essential for reducing emissions and promoting energy conservation. Furthermore, technological innovation is required for the most efficient use of both renewable and traditional energy sources. In addition, TI can help with the development of new renewable energy sources. Technological innovation also increases renewable energy capacity, increasing the likelihood that renewable energy will be able to satisfy future energy demand. Finally, the association between $\mathrm{CO}_{2}$ and globalization has a theoretical basis: as economies become more globalized, the consumption of energy increases. It is often thought that as globalization progresses, trade barriers fall, increasing the revenue and output of a nation. An increase in energy consumption is linked to an increase in production and income. Because it is often accepted that more globalization is linked to higher levels of economic expansion, it is also widely known that globalization helps to alleviate environmental deterioration; otherwise, if it is not eco-friendly, it promotes environmental destruction. Drawing from the above discussions, the research theoretical model is as follows:

$C O_{2 t}=f\left(G D P_{t}, T I_{t}, G L O_{t}\right)$

where TI, GDP, $\mathrm{CO}_{2}$, and GLO denote technological innovation, economic growth, carbon emissions, and globalization.

\section{Model and data}

The current paper analyzed the overall technological innovation as well as the effect of patent resident and patent nonresident influence on carbon emissions $\left(\mathrm{CO}_{2}\right)$ utilizing Sweden as a case study. As discussed in the introduction, technological innovation and it disaggregate (patent resident and patent nonresident) can have a positive and negative impacts on $\mathrm{CO}_{2}$ emissions. This paper utilized $\mathrm{CO}_{2}$ as a proxy for the degradation of the environment. According to Adebayo and Kirikkaleli (2021), while assessing the impact of technological innovation on $\mathrm{CO}_{2}$, it is important to account for GDP (economic growth). Since GDP (economic growth) is one of the major drivers of environmental pollution, the absence of GDP data may result in the omitted variable prejudice issue (Solarin et al. 2017; Dogan and Inglesi-Lotz. 2020; Kihombo et al. 2021). As stated by Akinsola et al. (2021), an upsurge in economic expansion is connected with the deterioration of the environment. As a result, the model below is used to investigate the total influence of technological innovation on carbon emissions.

$C O_{2 t}=\vartheta_{0}+\vartheta_{1} G D P_{t}^{+}+\vartheta_{2} G D P_{t}^{-}+\vartheta_{3} T I_{t}^{+}+\vartheta_{4} T I_{t}^{-}+\vartheta_{5} D U M+\varepsilon_{t}$

In Eq. $1, \mathrm{CO}_{2}$ stands for environmental pollution proxied by carbon emissions. GDP stand for economic growth and TI represents technological innovation. Also, +and- represent positive and negative shocks, respectively. DUM, t, and $\varepsilon$ illustrate the dummy variable, period, and error terms. Since the aggregate model is our primary model, we reassessed this connection in the second framework but added globalization (GLOB) for reliability reasons. Equation 2 depicts the second mode as follows:

$$
\begin{aligned}
C O_{2 t}= & \vartheta_{0}+\vartheta_{1} G D P_{t}^{+}+\vartheta_{2} G D P_{t}^{-}+\vartheta_{3} T I_{t}^{+} \\
& +\vartheta_{4} T I_{t}^{-}+\vartheta_{3} G L O B_{t}^{+} \\
& +\vartheta_{4} G L O B_{t}^{-}+\vartheta_{5} D U M+\varepsilon_{t}
\end{aligned}
$$

The first two frameworks are concerned with aggregate analysis. We chose not to include additional independent variables in the model since the timeframe is constrained to 1980 to 2018 , and adjusting for more series in the case of yearly data with an acceptable lag length may generate distorted outcomes, given that our technique separates one variable favorable (unfavorable) shock. Following the completion of the aggregate study, we will investigate the impact of patent resident (PATR) and patent nonresident (PATNR) on $\mathrm{CO}_{2}$ emissions as well as the influence of globalization

$$
\begin{aligned}
& C O_{2 t}=\vartheta_{0}+\vartheta_{1} G D P_{t}^{+}+\vartheta_{2} G D P_{t}^{-} \\
& +\vartheta_{3} \text { PATR }_{t}^{+}+\vartheta_{4} \text { PATR }_{t}^{-}+\vartheta_{5} \text { PATNR }_{t}^{+} \\
& +\vartheta_{6} \text { PATNR }_{t}^{-}+\vartheta_{7} \text { GLOB }_{t}^{+} \\
& +\vartheta_{8} G L O B_{t}^{-}+\vartheta_{9} D U M+\varepsilon_{t}
\end{aligned}
$$

In Eq. 3, PATR and PATTNR stand for patent resident and patent nonresident, respectively.

This research is based on annual data from 1980 to 2018. The beginning period is chosen, centered on the availability of data for technological innovation, whereas the ending year (2018) is chosen based on globalization data unavailability after 2018. The data on $\mathrm{CO}_{2}$ is obtained from BP statistics, TI and GDP are gathered 
Table 1 Data description

\begin{tabular}{llll}
\hline Variables & Sign & Measure & Source \\
\hline Carbon emissions & $\mathrm{CO}_{2}$ & Metric tons per capita & BP \\
Globalization & GLOB & Total KOF index of globalization & Gygli et al. 2019 \\
Economic growth & GDP & GDP per capita & WDI \\
Technological Innovation & TI & Addition of patent resident and nonresident & WDI \\
Patent resident & PATR & Patent resident & WDI \\
Patent nonresident & PATNR & Patent nonresident & WDI \\
\hline
\end{tabular}

from the World Bank database, and GLO is gathered from the KOF index. To enhance the analysis reliability and to standardize the data, this work transformed all variables into their natural logarithm. It will also make it possible to understand the coefficients as elasticities. Table 1 lists the variables and their definitions.

\section{Methodology}

This research's econometric technique entails using nonlinear methodologies to investigate long-run effect connections. It is essential to check for nonlinearities in the variables before using NARDL. To accomplish this, the renowned BDS test developed by Broock et al. (1996) was used. This research used conventional (ADF, PP, and KPSS) unit root tests after meeting this pre-requirement. Nevertheless, after receiving much condemnation for the findings of standard unit root approaches, we decided to use the (Zivot and Andrews. 2002) test, which is known for producing reliable results while compensating for a single data break. It is important to keep in mind that this test is only used to check if the variables are stationary at different levels, as prior tests may not be capable of distinguishing between unit root and structural break. Despite the fact that NARDL can handle fractional integration, the linear or NARDL cannot be employed if the dependent variable does not have a unit root at a level; hence, the unit root test, which can compensate for a structural break, is a viable option.

The present research utilized the NARDL to capture the association between $\mathrm{CO}_{2}$ emissions and regressors. The asymmetric ARDL technique can be utilized when the series are $1(0)$ or $1(1)$ or both $1(0)$ and 1 (1). The NARDL requires the acceptable lag selection, and the possible concern of endogeneity may be handled by choosing the appropriate lag duration. According to Shin et al. (2014), appropriate lag is also beneficial in fixing the challenges of possible multicollinearity in the NARDL. The ARDL technique yields both long- and short-run results. Furthermore, the convergence information is presented by ECT. The NARD equation is presented as follows:
The NARDL disintegrates variables based on their negative and positive shifts. Therefore, in our core model, economic growth, technological innovation, energy utilization, and renewable energy use are dissolved into negative and positive movements. As earlier stated in Eq. 2, we have already converted series into shocks $\left(G D P^{+}, G D P^{-}, T I^{+}, T I^{-} G L O B^{+}, G L O B^{-}\right)$and in Eq. $3\left(G^{2} P^{+}, G^{+} P^{-}\right.$, PATR $^{+}$, PATR $^{-}$, PATNR $^{+}$, PATNR $\left.^{-}, G O B^{+}, G L O B^{-}\right)$, respectively.

Furthermore, under the first model, the partial total of changes in economic growth, globalization, and technological innovation are as follows.

$G D P^{+}=\sum_{i=1}^{t} \Delta G D P^{+}+\sum_{i=1}^{t} \max \left(G D P_{i,} O\right)$
$G D P^{-}=\sum_{i=1}^{t} \Delta G D P^{-}+\sum_{i=1}^{t} \min \left(G D P_{i,} O\right)$

$T I^{+}=\sum_{i=1}^{t} \Delta T I^{+}+\sum_{i=1}^{t} \max \left(T I_{i,} O\right)$

$T I^{-}=\sum_{i=1}^{t} \Delta T I^{-}+\sum_{i=1}^{t} \min \left(T I_{i,} O\right)$

$G L O B^{+}=\sum_{i=1}^{t} \Delta G L O B^{+}+\sum_{i=1}^{t} \max \left(G L O B_{i} O\right)$

$G L O B^{-}=\sum_{i=1}^{t} \Delta G L O B^{-}+\sum_{i=1}^{t} \min \left(G L O B_{i} O\right)$

The partial sum for the second model was not incorporated to avoid several equations which will be too cumbersome for readers to comprehend. Therefore, the following equation can be utilized in a NARDL context to integrate both long-run and short-run dynamics. Equations 10 and 11 elucidate model 1 and model 2 long- and short-run associations. 
Table 2 Descriptive statistics

\begin{tabular}{lllllll}
\hline & $\mathrm{CO}_{2}$ & GDP & GLOB & PATNR & PATR & TI \\
\hline Mean & 0.785994 & 4.634613 & 1.921821 & 2.877256 & 3.485524 & 3.18139 \\
Median & 0.805225 & 4.633125 & 1.932614 & 2.817565 & 3.513218 & 3.176431 \\
Maximum & 0.935691 & 4.762763 & 1.952891 & 3.706376 & 3.631748 & 3.659898 \\
Minimum & 0.622043 & 4.495826 & 1.872715 & 2.170262 & 3.264346 & 2.764859 \\
Std. Dev & 0.079638 & 0.087439 & 0.027522 & 0.367458 & 0.120081 & 0.231525 \\
Skewness & -0.56252 & -0.0234 & -0.37911 & 0.470601 & -0.40463 & 0.245385 \\
Kurtosis & 2.603101 & 1.541024 & 1.483816 & 2.703057 & 1.668353 & 2.242898 \\
Jarque-Bera & 2.312804 & 3.462556 & 4.669786 & 1.582807 & 3.945824 & 1.322847 \\
Probability & 0.314616 & 0.177058 & 0.096821 & 0.453208 & 0.139051 & 0.516116 \\
\hline
\end{tabular}

$$
\begin{aligned}
& \Delta C O_{2 t}=\beta_{0}+\beta_{1} C_{2 t-i}+\beta_{2} \mathrm{GDP}_{t-i}^{+}+\beta_{3} \mathrm{GDP}_{t-i}^{-}+\beta_{4} \mathrm{TI}_{t-i}^{+} \\
& +\beta_{5} \mathrm{TI}_{t-i}^{-}+\beta_{6} \mathrm{GLOB}_{t-i}^{+} \\
& +\beta_{7} \mathrm{GLOB}_{t-i}^{-}+\sum_{i=1}^{t} \vartheta_{1} \Delta \mathrm{CO}_{2 t-i} \\
& +\sum_{i=1}^{t} \vartheta_{2} \Delta \mathrm{GDP}_{t-i}^{+}+\sum_{i=1}^{t} \vartheta_{3} \Delta \mathrm{GDP}_{t-i}^{-} \\
& +\sum_{i=1}^{t} \vartheta_{4} \Delta \mathrm{TI}_{t-i}^{+} \\
& +\sum_{i=1}^{t} \vartheta_{5} \Delta \mathrm{TI}_{t-i}^{-}+\sum_{i=1}^{t} \vartheta_{6} \Delta \mathrm{GLOB}_{t-i}^{+} \\
& +\sum_{i=1}^{t} \vartheta_{7} \Delta \mathrm{GLOB}_{t-i}^{-}+\vartheta_{8} D U M_{t-i}+\varepsilon_{t} \\
& \triangle C O_{2 t}=\beta_{0} \\
& +\beta_{1} \mathrm{CO}_{2 t-i} \\
& +\beta_{2} \mathrm{GDP}_{t-i}^{+} \\
& +\beta_{3} \mathrm{GDP}_{t-i}^{-} \\
& +\beta_{4} \mathrm{PATR}_{t-i}^{+} \\
& +\beta_{5} \text { PATR }_{t-i}^{-}+\beta_{6} \text { PATNR }_{t-i}^{+}+\beta_{7} \text { PATNR }_{t-i}^{-} \\
& +\beta_{8} \mathrm{GLOB}_{t-i}^{+}+\beta_{9} \mathrm{GLOB}_{t-i}^{-}+\sum_{i=1}^{t} \vartheta_{1} \Delta C O_{2 t-i} \\
& +\sum_{i=1}^{t} \vartheta_{2} \Delta \mathrm{GDP}_{t-i}^{+} \\
& +\sum_{i=1}^{t} \vartheta_{3} \Delta \mathrm{GDP}_{t-i}^{-}+\sum_{i=1}^{t} \vartheta_{4} \Delta \mathrm{PATR}_{t-i}^{+} \\
& +\sum_{i=1}^{t} \vartheta_{5} \Delta \mathrm{PATR}_{t-i}^{-}+\sum_{i=1}^{t} \vartheta_{6} \Delta R \mathrm{PATNR}_{t-i}^{+} \\
& +\sum_{i=1}^{t} \vartheta_{7} \Delta \mathrm{PATNR}_{t-i}^{-}+\sum_{i=1}^{t} \vartheta_{8} \Delta \mathrm{GLOB}_{t-i}^{+} \\
& +\sum_{i=1}^{t} \vartheta_{9} \Delta \mathrm{GLOB}_{t-i}^{-}+\vartheta_{10} D U M_{t-i}+\varepsilon_{t}
\end{aligned}
$$

The NARDL bound test is utilized to capture the long-run association between $\mathrm{CO}_{2}$ emissions and the regressors. The null hypothesis is rejected if the $F$-statistic is greater than the lower and upper critical values. With the addition of an error correction term (ECT), the preceding equation can simply be converted into an error correction model.

$$
\begin{aligned}
& \Delta \mathrm{CO}_{2 t}=\beta_{0} \\
& +\sum_{i=1}^{t} \vartheta_{1} \Delta C O_{2 t-i}+\sum_{i=1}^{t} \vartheta_{2} \Delta \mathrm{GDP}_{t-i}^{+} \\
& +\sum_{i=1}^{t} \vartheta_{3} \Delta \mathrm{GDP}_{t-i}^{-}+\sum_{i=1}^{t} \vartheta_{4} \Delta \mathrm{TI}_{t-i}^{+}+\sum_{i=1}^{t} \vartheta_{5} \Delta \mathrm{TI}_{t-i}^{-} \\
& +\sum_{i=1}^{t} \vartheta_{6} \Delta \mathrm{GLOB}_{t-i}^{+} \\
& +\sum_{i=1}^{t} \vartheta_{7} \Delta \mathrm{GLOB}_{t-i}^{-}+\vartheta_{8} D U M_{t-i} \\
& +\omega_{9} E C T_{t-1}+\varepsilon_{t} \\
& \Delta C O_{2 t}=\beta_{0}+\sum_{i=1}^{t} \vartheta_{1} \Delta C O_{2 t-i}+\sum_{i=1}^{t} \vartheta_{2} \Delta \mathrm{GDP}_{t-i}^{+} \\
& +\sum_{i=1}^{t} \vartheta_{3} \Delta \mathrm{GDP}_{t-i}^{-}+\sum_{i=1}^{t} \vartheta_{4} \Delta \mathrm{PATR}_{t-i}^{+} \\
& +\sum_{i=1}^{t} \vartheta_{5} \Delta \mathrm{PATR}_{t-i}^{-}+\sum_{i=1}^{t} \vartheta_{6} \Delta \mathrm{PATNR}_{t-i}^{+}+\sum_{i=1}^{t} \vartheta_{7} \Delta \mathrm{PATNR}_{t-i}^{-} \\
& +\sum_{i=1}^{t} \vartheta_{8} \Delta \mathrm{GLOB}_{t-i}^{+}+\sum_{i=1}^{t} \vartheta_{9} \Delta \mathrm{GLOB}_{t-i}^{-}+\vartheta_{10} D U M_{t-i}+\omega_{11} E C T_{t-1}+\varepsilon_{t}
\end{aligned}
$$

\section{Findings and discussions}

\section{Descriptive statistics and unit root outcomes}

Understanding the basic information of the variables of research is essential. Therefore, Table 2 presents the descriptive statistics of the series. GDP (4.6346) has the highest mean, followed by PATR (3.485524), TI (3.18139), PATNR (2.87725), GLOB (1.9218), and $\mathrm{CO}_{2}$ (0.785994). The skewness results showed that $\mathrm{CO}_{2}$, GDP, GLOB, and PATR are skewed negatively, whereas PATNR and TI are skewed positively. Furthermore, the value of kurtosis showed that all series are platykurtic. Furthermore, we utilized the RADAR chart (see Fig. 3) to present the variables' descriptive statistics. Moreover, in this research, we applied a series of conventional unit root tests (ADF, ERS, and PP) to identify the series order of integration, and the outcomes are presented in Table 3. The outcomes from these tests showed that all the series are I (1). If there is a break in series, the traditional 
Fig. 3 Graphical flow of analysis. a Spectral causality from PATNR to $\mathrm{CO}_{2}$

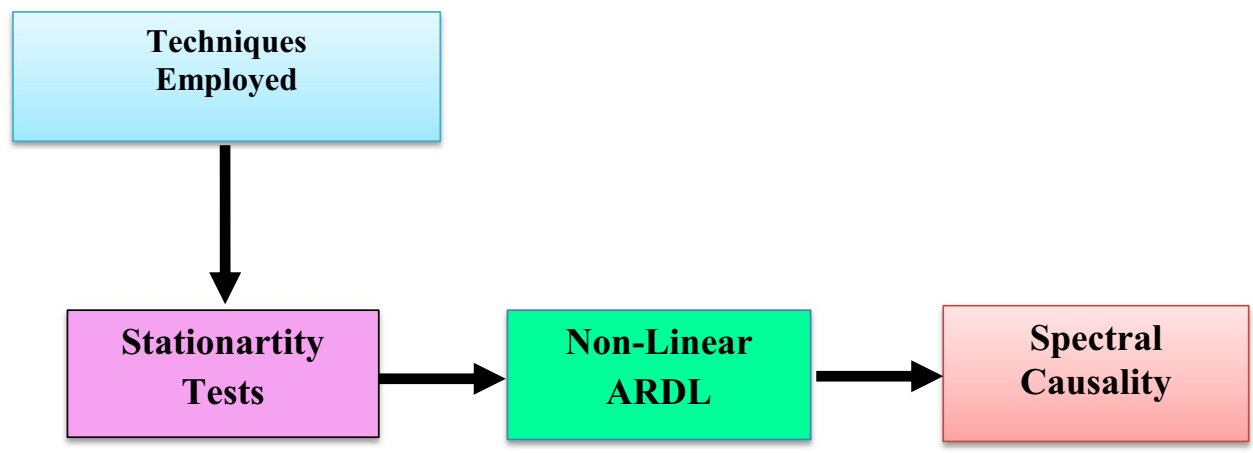

Table 3 Conventional unit root

\begin{tabular}{|c|c|c|c|c|c|c|}
\hline & \multicolumn{2}{|l|}{$\mathrm{ADF}$} & \multicolumn{2}{|l|}{ PP } & \multicolumn{2}{|l|}{ ERS } \\
\hline & Level & First difference & Level & First difference & Level & First difference \\
\hline $\mathrm{CO}_{2}$ & -1.9920 & $-6.4977 *$ & -2.0047 & $-6.8544^{*}$ & -2.0238 & $-6.6304 *$ \\
\hline GDP & -2.2617 & $-4.3991 *$ & -1.9086 & $-4.3253^{*}$ & -2.3780 & $-4.4484^{*}$ \\
\hline TI & -2.1666 & $-5.7870^{*}$ & -2.2222 & $-5.7929 *$ & -2.0839 & $-5.8175^{*}$ \\
\hline PATR & -1.3455 & $-4.8797 *$ & -1.5440 & $-4.8917 *$ & -1.3688 & $-4.9501 *$ \\
\hline PATNR & -2.4989 & $-6.5519 *$ & -2.3106 & $-13.301 *$ & -2.3374 & $-6.6148^{*}$ \\
\hline GLOB & -0.9799 & $-5.1310 *$ & -1.3548 & $-5.1745^{*}$ & -1.1261 & $-5.2235^{*}$ \\
\hline
\end{tabular}

* stands for $P<0.01$.

Fig. 4 RADAR chart

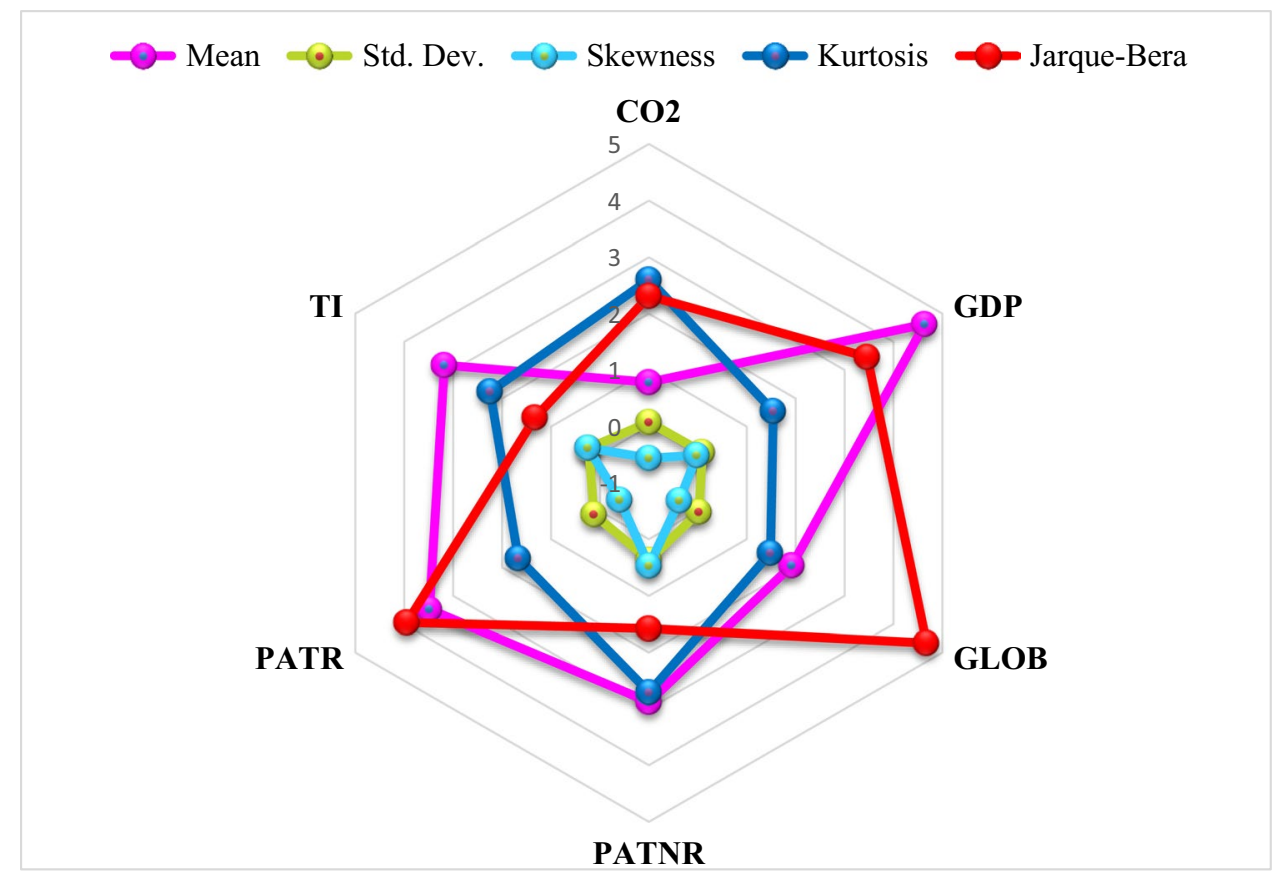

(ADF, PP, and ERS) tests would yield misleading outcomes. Time series data are susceptible to disturbances as an outcome of structural and macroeconomic events, including policies that might undermine the stability of the variables that define a certain economic phenomenon. Inflation, natural catastrophes, and recessions, as well as health concerns like the COVID-19 pandemic are all potential causes of economic shocks with long-term consequences. These can influence the results of any research conducted in that country. Traditional unit root tests frequently overlook such shocks and account for them as stationary (Fig. 4). Resultantly, we applied the Zivot-Andrews test developed by Zivot and Andrews (2002). The outcomes are portrayed in Table 4, which show that the series are I (1) with $\mathrm{CO}_{2}$, GDP, TI, PATR, PATNR, and 
Table 4 ZA unit root test

\begin{tabular}{llllll}
\hline & \multicolumn{2}{l}{ Level } & & \multicolumn{2}{l}{ First difference } \\
\cline { 2 - 3 } \cline { 5 - 6 } \cline { 5 - 6 } & $T$ statistics & Break year & & $T$ statistics & Break year \\
\hline CO $_{2}$ & -4.6378 & 2002 & & $-5.9276^{*}$ & 1997 \\
GDP & -3.2252 & 1998 & & $-5.6985^{*}$ & 1994 \\
TI & -2.9395 & 2012 & & $-6.3475^{*}$ & 2001 \\
PATR & -3.7603 & 1993 & & $-5.8753^{*}$ & 2001 \\
PATNR & -3.7995 & 2012 & $-5.7750^{*}$ & 2001 \\
GLOB & -3.3305 & 1993 & $-8.0332^{*}$ & 1991 \\
\hline
\end{tabular}

* stands for $P<0.01$
GLOB having breaks of 1997, 1994, 2001, 2001, 2001, and 1991, respectively.

\section{Cointegration outcomes}

After confirming the series order of integration, we proceed to evaluate the long-run interrelation of the two models. In doing so, we apply the NARDL bounds test to identify the long-run connection. Table 5 displays the outcomes of the NARDL bounds test in the two models. The outcomes of the bounds test in the first model show evidence of a long-run interrelation between $\mathrm{CO}_{2}$ and the

Table 5 NARDL cointegration

\begin{tabular}{|c|c|c|c|c|}
\hline \multicolumn{3}{|c|}{ Models estimated } & $F$ statistics & AIC lags \\
\hline \multicolumn{3}{|c|}{ Model 1: $\left(\mathrm{CO}_{2} / G D P^{+}, G D P^{-}, G L O B^{+}, G L O B^{-}, T I^{+}, T I^{-}, D U M\right)$} & $7.074^{*}$ & $2,2,2,1,2,1,0$ \\
\hline \multicolumn{3}{|c|}{ Model 2: $\left(\mathrm{CO}_{2} / G D P^{+}, G D P^{-}, G L O B^{+}, G L O B^{-}, P A T N R^{+}, P^{\prime}{ }^{-} R^{-} P A T R^{+}, P_{T A R^{-}}, D U M\right)$} & $12.27 *$ & $2,0,2,0,0,0,1,2,0$ \\
\hline & Mode & & Model-2 & \\
\hline Sig & $1(\mathbf{0})$ & $1(1)$ & $1(\mathbf{0})$ & $1(1)$ \\
\hline $10 \%$ & 2.12 & 3.23 & 1.95 & 3.06 \\
\hline $5 \%$ & 2.45 & 3.61 & 2.22 & 3.39 \\
\hline $2.5 \%$ & 2.75 & 3.99 & 2.48 & 3.70 \\
\hline $1 \%$ & 3.15 & 4.43 & 2.79 & 4.10 \\
\hline
\end{tabular}

* stands for $P<0.01$. AIC is utilized for optimum lag length.

Table 6 NARDL model 1

\begin{tabular}{|c|c|c|c|c|c|c|c|c|}
\hline \multirow[t]{2}{*}{ Variables } & \multicolumn{4}{|c|}{ Long-run outcomes } & \multicolumn{4}{|c|}{ Short-run outcomes } \\
\hline & Coefficients & & $t$ stat & $P$ value & Variables & Coefficients & $t$ stat & $P$ value \\
\hline $\mathrm{GDP}^{+}$ & $-0.7353^{*}$ & & -3.1348 & 0.0073 & $\mathrm{GDP}^{+}$ & $-1.1579 *$ & -3.7195 & 0.0023 \\
\hline $\mathrm{GDP}^{-}$ & $-0.1579 * * *$ & & -1.9331 & 0.0737 & $\mathrm{GDP}^{-}$ & 0.1239 & 1.6141 & 0.1288 \\
\hline $\mathrm{GLOB}^{+}$ & $1.5177 * *$ & & 2.9147 & 0.0113 & $\mathrm{GLOB}^{+}$ & 0.0361 & 1.3841 & 0.1896 \\
\hline $\mathrm{GLOB}^{-}$ & -2.0288 & & -0.9314 & 0.3674 & $\mathrm{GLO}^{-}$ & -0.0754 & -0.1783 & 0.8612 \\
\hline $\mathrm{TI}^{+}$ & $-0.1726^{* *}$ & & -2.7753 & 0.0149 & $\mathrm{TI}^{+}$ & $-0.1164 * *$ & -2.7605 & 0.0153 \\
\hline $\mathrm{TI}^{-}$ & $0.1668 * *$ & & 2.6490 & 0.0191 & $\mathrm{TI}^{-}$ & $0.0831 * * *$ & 1.9197 & 0.0755 \\
\hline DUM & 0.0277 & & 1.7488 & 0.1022 & ECT(-) & $-0.8147^{*}$ & -9.2136 & 0.0000 \\
\hline $\mathrm{C}$ & 0.7034 & & 3.7089 & 0.0023 & & & & \\
\hline \multicolumn{9}{|c|}{ Diagnostic tests } \\
\hline$R^{2}$ & & 0.98 & & & & & & \\
\hline $\operatorname{Adj}^{2}$ & & 0.97 & & & & & & \\
\hline DW statistics & & 2.756 & & & & & & \\
\hline$F$ statistics & & $468.02[0.000]$ & & & & & & \\
\hline J-B normality & & $0.228[0.892]$ & & & & & & \\
\hline$\chi^{2} \mathrm{LM}$ & & $1.156[0.333]$ & & & & & & \\
\hline$\chi^{2} \mathrm{ARCH}$ & & $0.819[0.661]$ & & & & & & \\
\hline$\chi^{2}$ RESET & & $0.451[0.658]$ & & & & & & \\
\hline
\end{tabular}


Table 7 NARDL model 2

\begin{tabular}{|c|c|c|c|c|c|c|c|c|}
\hline \multirow[t]{2}{*}{ Variables } & \multicolumn{4}{|c|}{ Long-run outcomes } & \multicolumn{4}{|c|}{ Short-run outcomes } \\
\hline & Coefficients & & $t$ statistics & $P$ value & Variables & Coefficients & $t$ statistics & $P$ value \\
\hline $\mathrm{GDP}^{+}$ & $-1.1628 *$ & & -3.1615 & 0.0075 & $\mathrm{GDP}^{+}$ & $-1.1628 *$ & -5.5439 & 0.0001 \\
\hline $\mathrm{GDP}^{-}$ & $-1.1313^{*}$ & & -4.6874 & 0.0004 & $\mathrm{GDP}^{-}$ & $0.4564 * *$ & 2.1722 & 0.0489 \\
\hline $\mathrm{GLOB}^{+}$ & $1.2527 *$ & & 4.5989 & 0.0005 & $\mathrm{GLOB}^{+}$ & 0.2700 & 0.7957 & 0.4405 \\
\hline $\mathrm{GLOB}^{-}$ & -1.6782 & & -0.9607 & 0.3542 & $\mathrm{GLOB}^{-}$ & $-1.2527 *$ & -8.5899 & 0.0000 \\
\hline PATR $^{+}$ & $-0.6653 * *$ & & -3.8380 & 0.0021 & PATR $^{+}$ & $-0.1052 *$ & -8.1723 & 0.0000 \\
\hline PATR $^{-}$ & $0.0314 * *$ & & 2.9232 & 0.0119 & PATR $^{-}$ & $0.0642 *$ & 4.6403 & 0.0005 \\
\hline PATNR $^{+}$ & $-0.1052 *$ & & -4.8765 & 0.0003 & PATNR $^{+}$ & $-0.2017 *$ & -6.851 & 0.0000 \\
\hline PATNR $^{-}$ & $0.0611 * * *$ & & 1.9674 & 0.0708 & PATNR $^{-}$ & $0.0642 *$ & 4.6403 & 0.0005 \\
\hline DUM & 0.0042 & & 0.3252 & 0.7501 & ECT(-) & -0.4898 & -15.085 & 0.0000 \\
\hline $\mathrm{C}$ & 0.9262 & & 7.9780 & 0.0000 & & & & \\
\hline \multicolumn{9}{|c|}{ Diagnostic tests } \\
\hline$R^{2}$ & & 0.97 & & & & & & \\
\hline $\operatorname{Adj}^{2}$ & & 0.96 & & & & & & \\
\hline DW statistics & & 2.695 & & & & & & \\
\hline$F$ statistics & & $181.33[0.000]$ & & & & & & \\
\hline J-B normality & & $1.125[0.569]$ & & & & & & \\
\hline$\chi^{2} \mathrm{LM}$ & & $1.160[0.293$ & & & & & & \\
\hline$\chi^{2} \mathrm{ARCH}$ & & $1.338[0.298]$ & & & & & & \\
\hline$\chi^{2}$ RESET & & $0.870[0.394]$ & & & & & & \\
\hline
\end{tabular}

Table 8 Long-run asymmetries

\begin{tabular}{llllll}
\hline Variables & \multicolumn{2}{l}{ Model 1 } & & & Model 2 \\
\cline { 2 - 3 } \cline { 5 - 6 } & $\chi^{2}$ Chi-square & Probability & & $\chi^{2}$ Chi-square & Probability \\
\hline GDP & $18.3943^{*}$ & 0.0000 & & $27.2769^{*}$ & 0.0000 \\
TI & $6.39049^{* *}$ & 0.0115 & & - & - \\
GLOB & 0.26329 & 0.6079 & & 1.80522 & 0.1791 \\
PATRS & - & - & & $6.04634^{* *}$ & 0.0139 \\
PATNRS & - & - & $6.27866^{* *}$ & 0.0122 \\
\hline
\end{tabular}

*, **, and *** portrays $P<0.01, P<0.05$, and $P<0.10$.

regressors since the $F$ statistics is greater than the lower and upper bounds critical values. Furthermore, in model 2 , there is evidence of a long-run association between $\mathrm{CO}_{2}$ and the regressors.

\section{NARDL long- and short-run outcomes}

After the cointegration between $\mathrm{CO}_{2}$ and the regressors is established in model 1 and model 2 , respectively, the current research proceeds to the long- and short-run evaluation. The $R^{2}$ values for model 1 and model 2 are 0.98 and 0.97 , respectively, which implies that $98 \%$ and $97 \%$ of the variation in the independent variables can explain $\mathrm{CO}_{2}$ emissions. The outcomes of the NARDL in model 1 and model 2 are presented in Tables 6,7 , and 8, respectively.
In models 1 and 2 , it is found that a positive (negative) upsurge in GDP exerts a negative influence on $\mathrm{CO}_{2}$. This outcome demonstrates that the favorable (unfavorable) effect of GDP helps in mitigating the degradation of the environment. The nonlinear relationship between $\mathrm{CO}_{2}$ emissions and economic growth suggests that Sweden is at the composite and technique stage where technological innovation and services dominate the economy. This indicates that Sweden does not prioritize economic growth at the expense of environmental damage. Several developed countries have followed this trend of environmentally friendly economic growth. As a consequence, the study's results will have major policy ramifications for Sweden and other developed economies. As a result, fulfilling the SDG 13 goals in Sweden will not be a problem. Several studies (Akinsola et al. 2021; Alola. 2019; Khan and Ozturk. 2021; Shahbaz et al. 2018; Solarin et al. 2017) on the association between $\mathrm{CO}_{2}$ emissions and economic growth have ignored the differential effects of a positive (negative) GDP shock on $\mathrm{CO}_{2}$ emissions. This result complies with the study of (Udemba, et al. 2021a, b), who found that a negative shock in GDP improves the quality of the environment in the Chile. However, the study of (Shahbaz et al. 2021) contradicts this finding. Their outcomes showed that an unfavorable shock in GDP does improve the quality of the environment in India. Similarly, using Algeria as a case study, the research of Udemba and 
Yalçıntaş (2021) found that a negative shock in GDP does not enhance environmental quality.

Furthermore, in model 1, it has been shown that a positive (negative) variation in technological innovation decreases (increase) $\mathrm{CO}_{2}$ emissions in Sweden. This suggests that technological innovation contributes to the mitigation of environmental degradation in Sweden. Therefore, a significant proportion of technological innovation is associated with eco-innovation in Sweden. In addition, this outcome is unsurprising given that Sweden is ranked second globally among the most innovative countries. ${ }^{1}$ The use of new technologies, patents, or concepts linked to environmental protection might explain the direct negative effects of technological innovation. As increasing emphasis is placed on climate change and carbon emissions, the invention and use of carbon-cutting technology accelerate. Storage technology, sustainable green building concepts, carbon fixation technology, carbon capture, combined heat and power production technology, and green chemistry methods are examples of these approaches. The reducing effects of these approaches have been validated in prior studies as well as in practice. As a result, authorities in Sweden should make green technology a priority in their innovation strategies. Several studies (Awosusi et al. 2021; Kihombo et al. 2021; Shan et al. 2021; Zhao et al. 2021) have validated this finding by establishing that TI helps in mitigating environmental degradation. However, other studies (Oladipupo et al. 2021; Udemba, et al. 2021a, b) have established that an upsurge in TI trigger degradation of the environment.

Moreover, in models 1 and 2, it is shown that a positive shock in globalization contributes to the degradation of the environment. On the other hand, an unfavorable shock in GLOB does not have a significant effect on $\mathrm{CO}_{2}$. This simply implies that globalization contributes to the degradation of the environment. The probable reason for this result is that the globalization process permits advanced economies to transmit sophisticated technology to emerging nations, which helps these nations enhance the division of labor and improve their comparative advantage. Furthermore, increased commerce enhances total factor productivity as a result of globalization. The transferal of foreign direct investment (FDI) and sophisticated technologies between industrialized and developing economies enhance economic activity. Furthermore, the globalization process facilitates investment via FDI and strengthens financial markets via financial liberalization. While this process benefits financial markets, economic growth, and commerce, it also increases the consumption of energy and degradation of the environment (Kirikkaleli et al. 2021). The studies of Shahbaz et al.

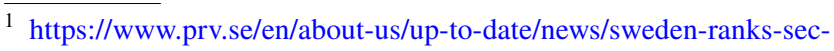
ond/
}

(2017) and Kirikkaleli et al. (2021) followed the same line of reasoning, claiming that globalization promotes a rapid increase in $\mathrm{CO}_{2}$ emissions due to the widespread use of energy in the production and consumption of goods and services in both emerging and developed nations. Nonetheless, the outcome contradicts the findings of Zaidi et al. (2019) and Haseeb et al. (2018), who established that globalization enhances the quality of the environment.

In model 2, we disaggregate technological innovation (patent resident and patent nonresident). Thus, a positive (negative) shift in patent resident (PATR) decreases (increases) $\mathrm{CO}_{2}$ emissions. In addition, a positive (negative) shift in patent nonresident (PATNR) decreases (increases) $\mathrm{CO}_{2}$ emissions. This simply means that a positive shock in PATR helps in mitigating environmental degradation. This implies that in the long run, both patent resident and patent nonresident have an asymmetric effect on carbon emissions in both direction and magnitude. The probable reason for this association is that Sweden has adopted a smart manufacturing method, which aids in the improvement of environmental quality. This implies that PATR can increase labor and/or capital productivity, which is one of the potential sources of pollution in the environment. This view was validated by the study of Ahmed and Le (2021), who established that a positive shift in technology stimulates the quality of the environment, while a negative shock contributes to the degradation of the environment in OECD countries. However, this outcome contradicts the findings of Demir et al. (2020) for Turkey, who established that patent technology contributes to the degradation of the environment. They further established that in developing nations, patent technological mitigates the quality of the environment. This view was also supported by the study of Ahmad et al. (2018) for China, who established that technological innovation reduces the quality of the environment.

In models 1 and 2, the short-run estimation produces findings that are equivalent to the long-run estimation. As anticipated, the ECT coefficients for models 1 and 2 are -0.8147 and -0.4898 , respectively, which are negative and significant. In addition, several diagnostic tests were conducted to ascertain whether the model is good in both models 1 and 2, respectively. The models exhibit no presence of serial correlation, no misspecification, no heteroskedasticity, and the residuals are normally distributed. Moreover, the CUSUM and CUSUM of Sq outcomes in Figs. 5a, b and 6a, b, respectively, show that the models are stable.

\section{Long-run asymmetries outcomes}

The Wald test was also used in the research to evaluate the long-run asymmetric association and significance. The Wald test outcomes are given in Table 6, with confirmation of a significant long-term asymmetric connection between the 

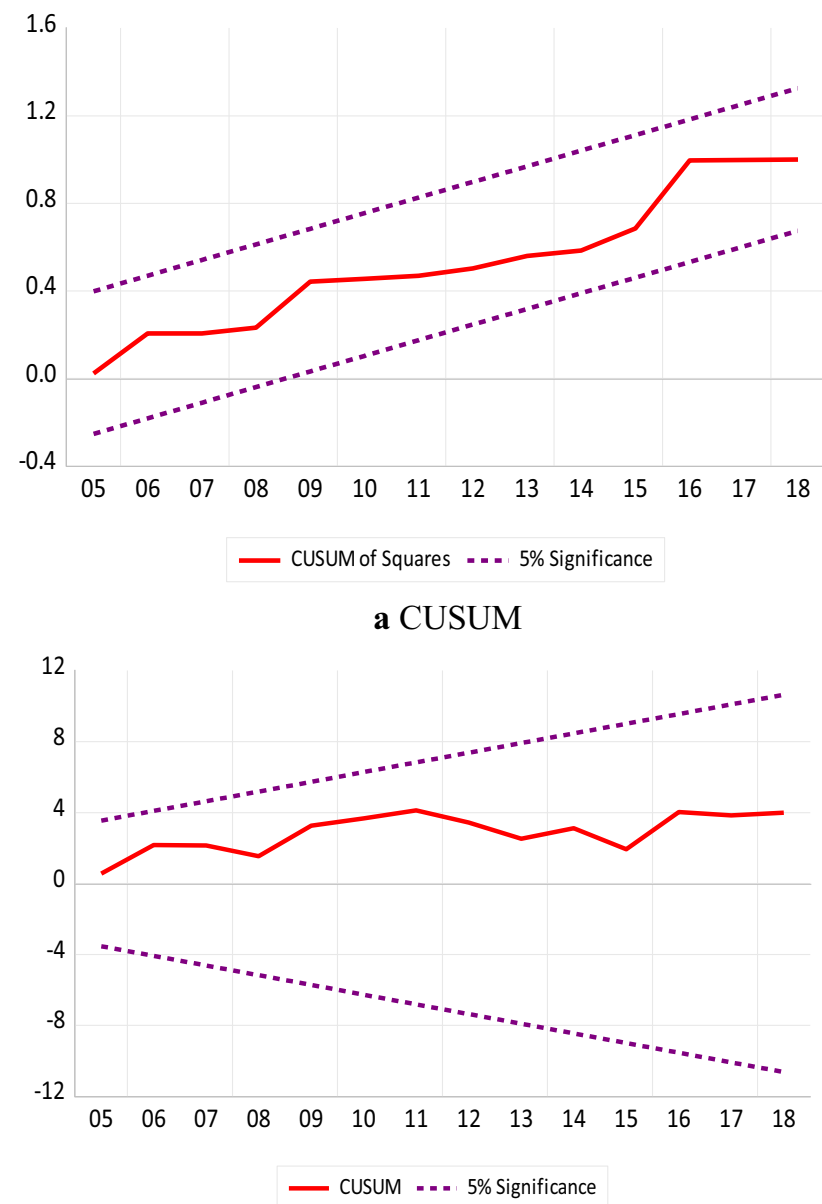

b CUSUM of Sq

Fig. 5 a CUSUM. b CUSUM of Sq

indicators at $5 \%$ for economic growth and technological innovation in Model-1. Furthermore, in Model-2, there is confirmation of a significant long-term asymmetric connection among the indicators at a 5\% level of significance for economic growth, patent residents, and patent nonresident. This supports the results of the NARDL estimates for the two models. These outcomes serve as a strong check for both the cointegration and error correction terms by providing credibility to their outcomes.

\section{Spectral causality outcomes}

The present study also applied the spectral causality test suggested by Breitung and Candelon (2006) to capture the causal connection between $\mathrm{CO}_{2}$ emissions and the regressors in Sweden between 1980 and 2018. The novelty of this approach is that it can capture causal linkages between series at different frequencies. The outcomes of this test are shown in Fig. 7a-h. The causal linkage between $\mathrm{CO}_{2}$ and the regressors at various frequencies $(0-1,1-2$, and $2-3)$ shows
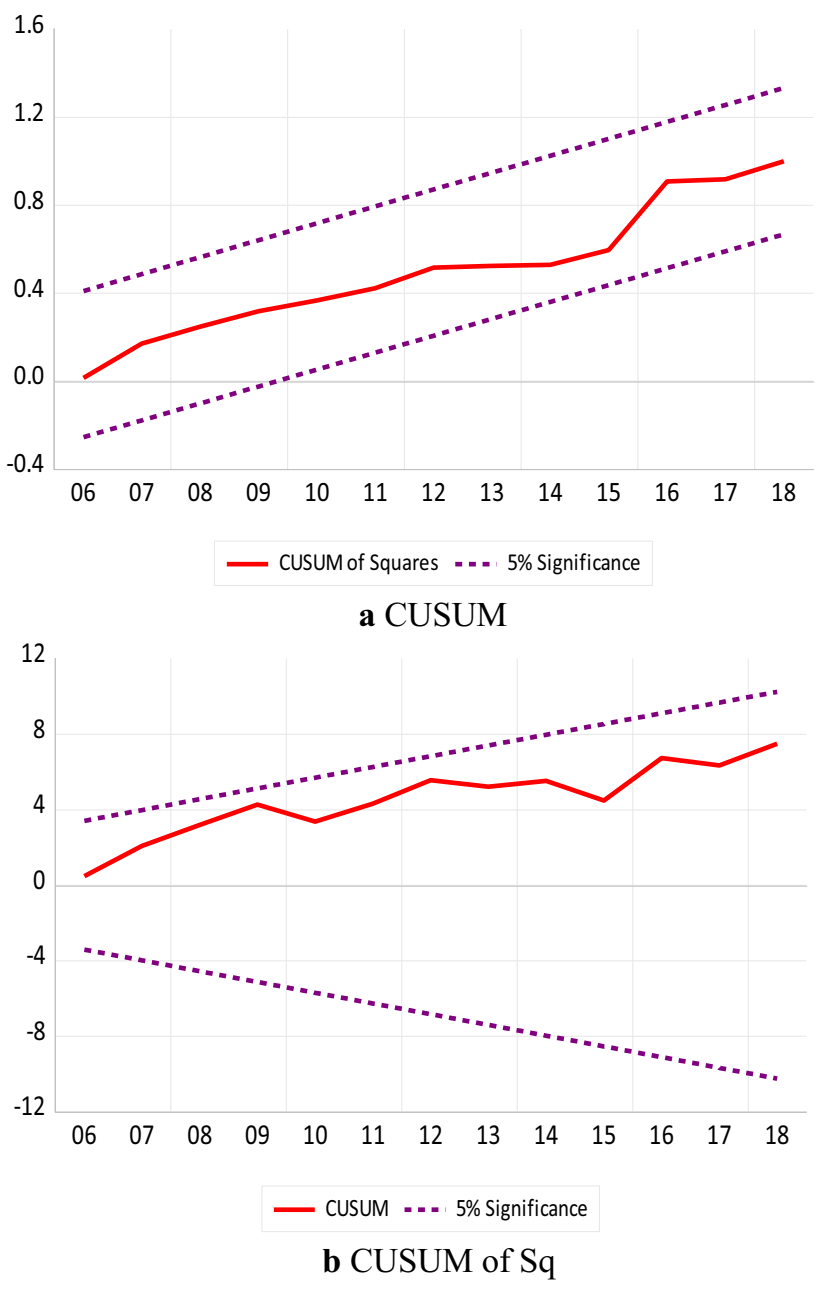

Fig. 6 a CUSUM. b CUSUM of Sq

long-, medium, and short-term connections. A permanent causality is defined as a frequency from 0 to 1 , whereas a temporary causality is defined as a frequency from 2 to 3. In Figs. 7a, b, c, d, and e, and 8, the upper line (purple) represents a significance level of $5 \%$ and the bottom line (green) represents a $10 \%$ level of significance. The statistical tests between the $(0, \pi)$ intervals at different frequencies are depicted by the (blue) curve.

Figure 7a depicts the presence of causality from TI to GDP in the short and medium run. Thus, the null hypothesis of no causality from $\mathrm{CO}_{2}$ to GDP for frequencies $0.01-0.5$ and $1.2-3$ is rejected at a level of significance of $10 \%$. Figure $7 \mathrm{~b}$ depicts the presence of causality from PATR to $\mathrm{CO}_{2}$ in the long run and medium term. Thus, the null hypothesis of no causality from PATR to $\mathrm{CO}_{2}$ for frequencies 1 and 1.5 is rejected at a level of significance of 5\%. Furthermore, Fig. $7 \mathrm{c}$ shows the presence of causality from nonresident patent (PATNR) to $\mathrm{CO}_{2}$ at all frequencies. Therefore, the null hypothesis of no causality from PATNR to $\mathrm{CO}_{2}$ cannot be rejected at a $1 \%$ level of significance. In addition, 


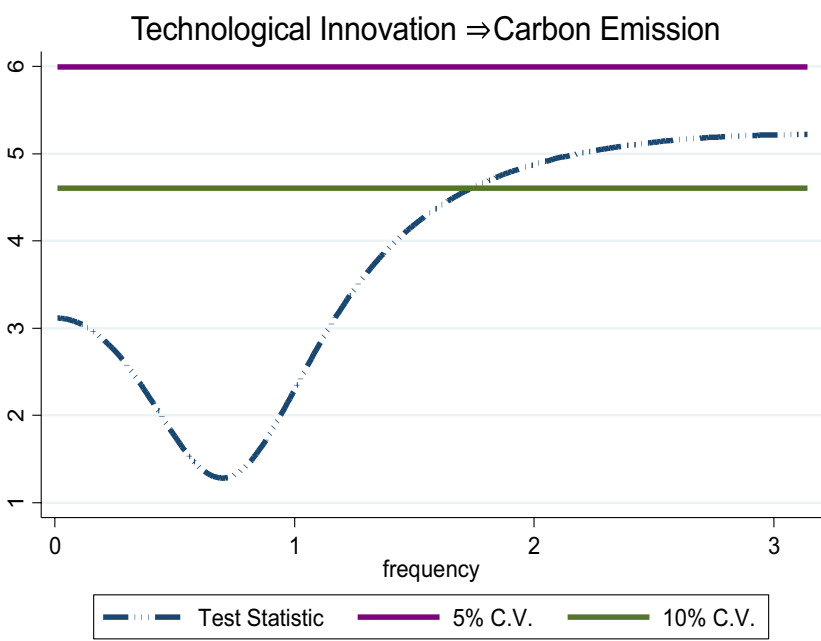

a Spectral causality from $\mathrm{CO}_{2}$ to GDP

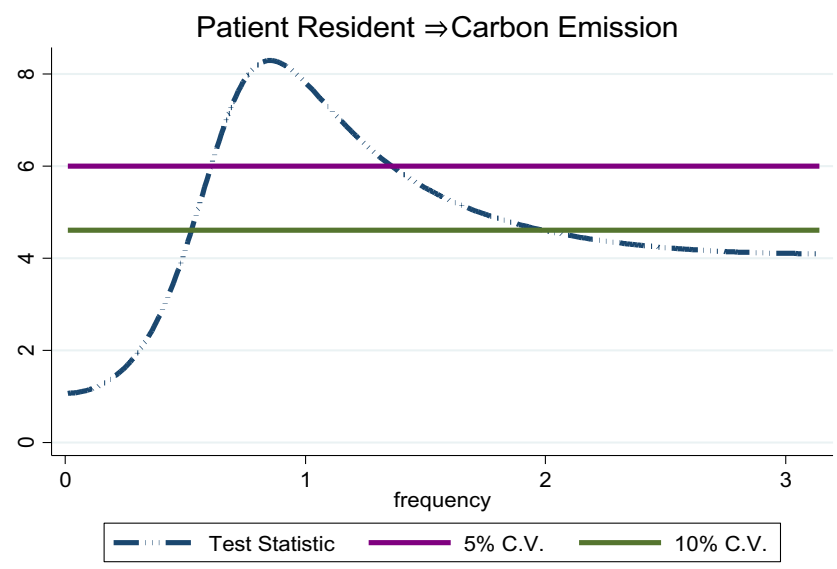

b Spectral causality from PATR to $\mathrm{CO}_{2}$

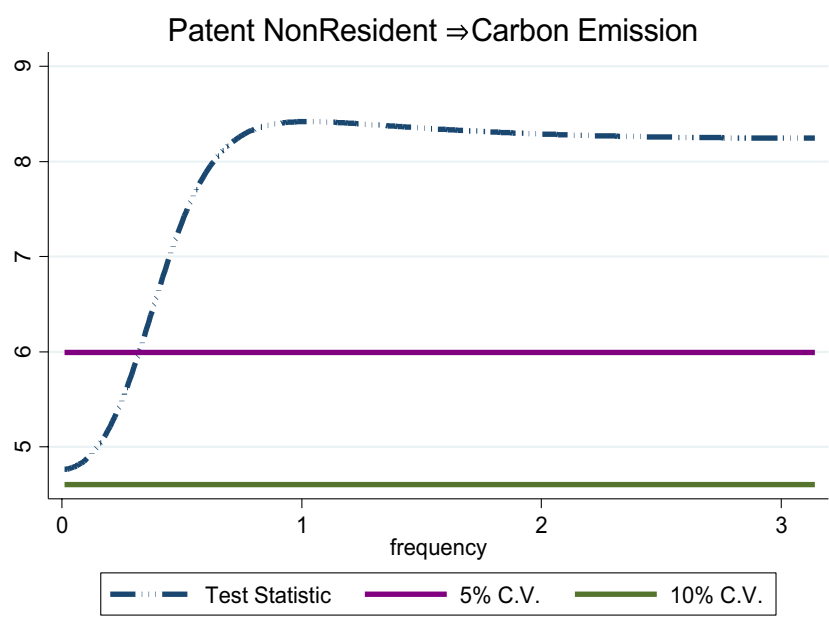

c Spectral causality from PATNR to $\mathrm{CO}_{2}$

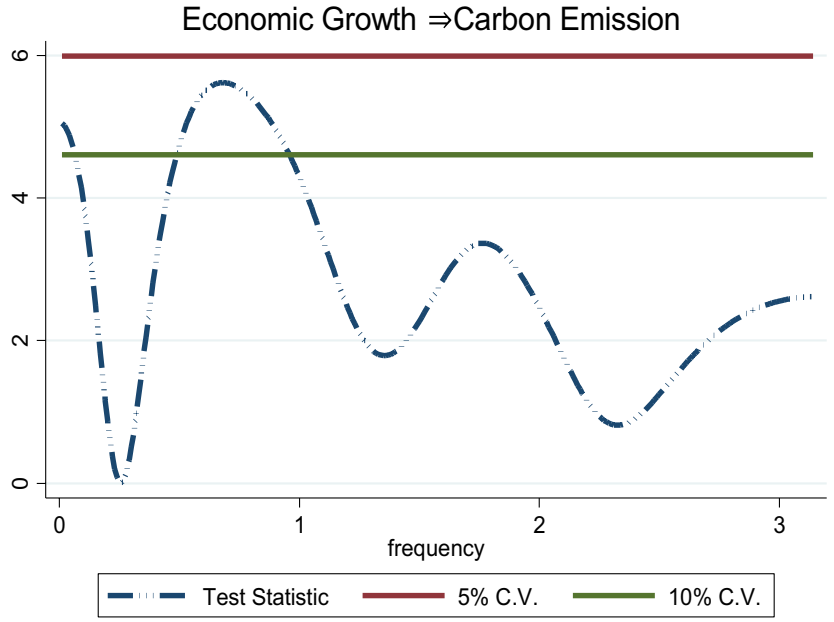

d Spectral causality from GDP to $\mathrm{CO}_{2}$

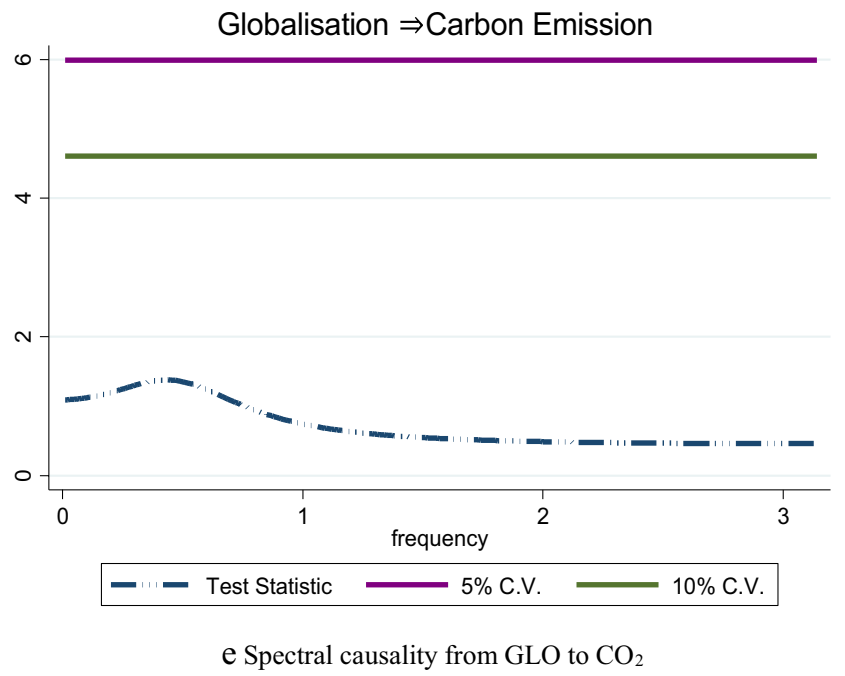

Fig. 7 a Spectral causality from $\mathrm{CO}_{2}$ to GDP. b Spectral causality from PATR to $\mathrm{CO}_{2}$. e Spectral causality from GDP to $\mathrm{CO}_{2}$ and spectral causality from GLO to $\mathrm{CO}_{2}$ 
Fig. 8 Study graphical representation

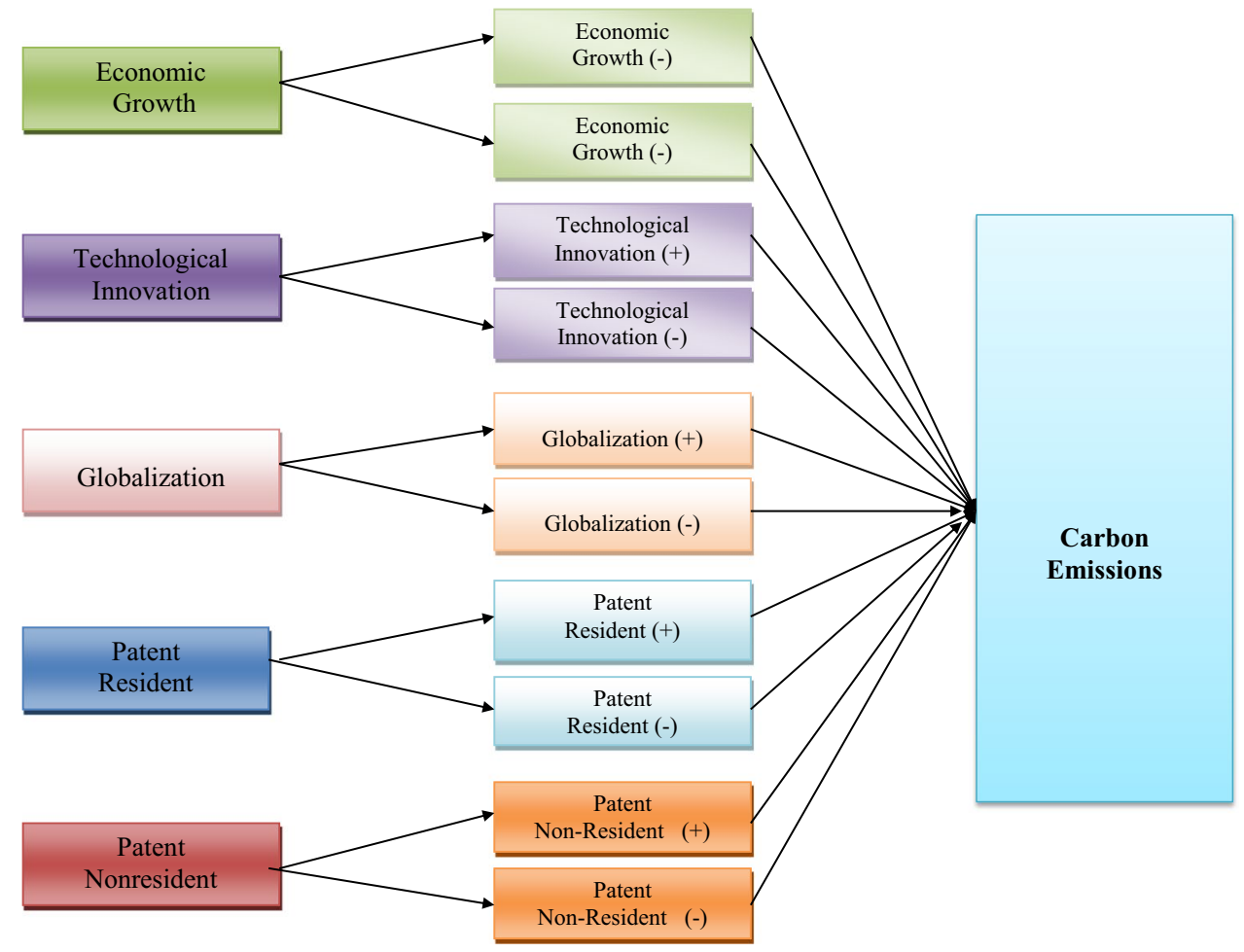

Fig. 7d shows the presence of causality from economic growth (GDP) to $\mathrm{CO}_{2}$ at 0.01-0.8 frequencies. Therefore, the null hypothesis of no causality from PATNR to $\mathrm{CO}_{2}$ is rejected at a $1 \%$ level of significance. Finally, Fig. 7e shows no presence of causality from globalization (GLO) to $\mathrm{CO}_{2}$ at all frequencies. Therefore, the null hypothesis of no causality from GLO to $\mathrm{CO}_{2}$ cannot be rejected at a $10 \%$ level of significance.

\section{Conclusion and policy direction}

\section{Conclusion}

The present research assesses and examines the nonlinear impact of economic growth, globalization, and technological innovation on $\mathrm{CO}_{2}$ emissions in Sweden by utilizing data from 1980 to 2018. To the best of the researchers' understanding, no existing studies have been conducted to examine the asymmetric, aggregated, and disaggregated technological innovation impact on $\mathrm{CO}_{2}$ emissions as well as the role of globalization. Thus, the gap in the literature is filled by this study. The research evaluates the explanatory variables' twofold (i.e., negative and positive) impact on $\mathrm{CO}_{2}$ emissions using the NARDL approach. In the two models, the $\mathrm{CO}_{2}$ function was built using a dummy variable that represented the structural break in the series. The study assesses the stationarity feature of the series by applying the ADF, PP, ERS, and ZA tests and their outcomes showed that series are I (1). Furthermore, the study applied the BDS test to capture the nonlinearity features of the series and the outcomes revealed that the series is nonlinear, which allows for the utilization of NARDL. In addition, the Wald test results show that the NARDL technique is correct and that the identified shocks are substantial. As a result, the research findings can be utilized to build a policy framework in Sweden to achieve the SDGs' goals.

The NARDL outcomes showed that a positive (negative) shock in GDP decreases $\mathrm{CO}_{2}$ emissions in Sweden. Furthermore, a positive shock in globalization leads to an upsurge in $\mathrm{CO}_{2}$. Nonetheless, a negative shock in globalization exerts an insignificant influence on $\mathrm{CO}_{2}$. In addition, a positive (negative) shock in aggregate technological innovation decreases (increase) $\mathrm{CO}_{2}$ in Sweden. Furthermore, the present study disaggregated technological innovation into patent residents and patent nonresident. The outcomes from this disaggregation showed that positive (negative) shock in patient residents decrease (increase) $\mathrm{CO}_{2}$. Similarly, a positive (negative) shock in patent nonresident leads to a decrease (increase) in $\mathrm{CO}_{2}$. Moreover, the spectral causality test was utilized to capture the causal interrelation between $\mathrm{CO}_{2}$ and the regressors. The outcomes from the causality test revealed that in the medium and long term, patent resident, patent, nonresident, and economic growth can predict $\mathrm{CO}_{2}$ in the long and medium term, while technological innovation can predict $\mathrm{CO}_{2}$ in the medium and short term. This implies that any policy channeled towards technological innovation and economic growth will impact $\mathrm{CO}_{2}$ emissions in Sweden. 


\section{Policy direction}

The following findings provide momentum for Swedish policymakers to stimulate investment in R \& D. Sweden's dedication to reducing emissions and creating a cleaner environment by increasing the amount of renewable energy in its energy portfolio may be credited with this achievement. As a result, the Swedish government should promote technologies that enhance energy efficiency. Energy intensity is one of the moderating effects of technological advancement. As a result, the government should promote and encourage this type of technology usage. Moreover, subsidies for companies that specialize in the manufacturing and assembly of renewable energy sources should be considered such as tax cuts and price control policies. This will allow them to boost production, making items more accessible and cheaper to both private and public interests. Additionally, since globalization degrades environmental quality, authorities should create ways of assessing the environmental viability of foreign investment and taking action against corporations that use outdated dirty technologies. Furthermore, foreign investors should be encouraged to utilize clean technologies and participate in greener energy projects by offering attractive incentives. International social partnerships should be promoted, and domestic media should be utilized to promote environmental awareness.

\section{Limitation of study and future direction}

Before drawing the research to a conclusion, it is important to note that no policy framework should be considered perfect, since it is impossible to capture all relevant policy aspects within the confines of a single framework, and this research is no exception. Only three variables have been utilized in formulating the framework, which is a limitation of the research. Additional studies could reproduce these findings in other developing and emerging nations, given that the asymmetric impact of components of technological innovation may differ in different nations.

Author Contributions Tomiwa Sunday Adebayo and Dervis Kirikkaleli: Conceptualization, supervision, and writing-review and editing. Tomiwa Sunday Adebayo: Methodology and software. Ibrahim Adeshola and Seun Damola Oladipupo: Conceptualization, investigation, resource, and writing-review and editing.

Funding This study received no specific financial support.

Data Availability Data is readily available at the request from the corresponding author.

\section{Declarations}

Ethical Approval This research complies with internationally accepted standards for research practice and reporting.

Consent to Participate Not applicable.

Consent to Publish Not applicable.

Conflict of Interest The authors declare that they have no conflict of interest.

\section{References}

Adebayo TS, Kirikkaleli D (2021) Impact of renewable energy consumption, globalization, and technological innovation on environmental degradation in Japan: application of wavelet tools. Environ Dev Sustain. https://doi.org/10.1007/ s10668-021-01322-2

Ahmad M, Khan Z, Ur Rahman Z, Khan S (2018) Does financial development asymmetrically affect $\mathrm{CO}_{2}$ emissions in China? An application of the nonlinear autoregressive distributed lag (NARDL) model. Carbon Management 9(6):631-644. https:// doi.org/10.1080/17583004.2018.1529998

Ahmed Z, Le HP (2021) Linking Information Communication Technology, trade globalization index, and $\mathrm{CO}_{2}$ emissions: evidence from advanced panel techniques. Environ Sci Pollut Res 28(7):8770-8781. https://doi.org/10.1007/s11356-020-11205-0

Akinsola GD, Kirikkaleli D, Bekun FV, Adebayo TS, Umarbeyli S, Osemeahon OS (2021) Economic performance of Indonesia amidst $\mathrm{CO}_{2}$ emissions and agriculture: a time series analysis. Environ Sci Pollut Res 2(4):1-15

Ali S, Yusop Z, Kaliappan SR, Chin L (2020) Dynamic common correlated effects of trade openness, FDI, and institutional performance on environmental quality: evidence from OIC countries. Environ Sci Pollut Res Int 27(11):11671-11682. https://doi.org/ 10.1007/s11356-020-07768-7

Ali S, Yusop Z, Kaliappan SR, Chin L (2021) Trade-environment nexus in OIC countries: fresh insights from environmental Kuznets curve using GHG emissions and ecological footprint. Environ Sci Pollut Res 28(4):4531-4548. https://doi.org/10. 1007/s11356-020-10845-6

Alola AA (2019) The trilemma of trade, monetary and immigration policies in the United States: accounting for environmental sustainability. Sci Total Environ 658:260-267. https://doi.org/10. 1016/j.scitotenv.2018.12.212

Alola AA, Adebayo TS, Onifade ST (2021) Examining the dynamics of ecological footprint in China with spectral Granger causality and quantile-on-quantile approaches. Int J Sustain Dev World Ecol 4(6):1-14

Awosusi AA, Kirikkaleli D, Akinsola GD, Adebayo TS, Mwamba $\mathrm{MN}$ (2021) $\mathrm{Can} \mathrm{CO}_{2}$ emissions and energy consumption determine the economic performance of South Korea? A time series analysis. Environ Sci Pollut Res 1-16

Bakhsh K, Rose S, Ali MF, Ahmad N, Shahbaz M (2017) Economic growth, $\mathrm{CO}_{2}$ emissions, renewable waste and FDI relation in Pakistan: new evidences from 3SLS. J Environ Manage 196:627-632. https://doi.org/10.1016/j.jenvman.2017.03.029

Balsalobre-Lorente D, Shahbaz M, Roubaud D, Farhani S (2018) How economic growth, renewable electricity and natural resources contribute to $\mathrm{CO}_{2}$ emissions? Energy Policy 113:356367. https://doi.org/10.1016/j.enpol.2017.10.050 
Bekun FV, Alola AA, Gyamfi BA, Yaw SS (2021) The relevance of EKC hypothesis in energy intensity real-output trade-off for sustainable environment in EU-27. Environ Sci Pollut Res. https:// doi.org/10.1007/s11356-021-14251-4

BP (2021) British Petroleum. https://www.bp.com/content/dam/bp/ business-sites/en/global/corporate/pdfs/energy-economics/stati stical-review/bp-stats-review-2019-china-insights.pdf. Accessed on 30 May 2021. https://www.bp.com/en/global/corporate/caree rs/professionals/locations/sweden.html\#/

Breitung J, Candelon B (2006) Testing for short- and long-run causality: a frequency-domain approach. Journal of Econometrics 132(2):363-378. https://doi.org/10.1016/j.jeconom.2005.02.004

Broock WA, Scheinkman JA, Dechert WD, LeBaron B (1996) A test for independence based on the correlation dimension. Economet Rev 15(3):197-235. https://doi.org/10.1080/074749396088003 53

Chaudhry IS, Ali S, Bhatti SH, Anser MK, Khan AI, Nazar R (2021) Dynamic common correlated effects of technological innovations and institutional performance on environmental quality: evidence from East-Asia and Pacific countries. Environ Sci Policy 124:313323. https://doi.org/10.1016/j.envsci.2021.07.007

Chen Y, Lee C-C (2020) Does technological innovation reduce $\mathrm{CO}_{2}$ emissions? Cross-Country Evidence Journal of Cleaner Production 263:121550. https://doi.org/10.1016/j.jclepro.2020.121550

Chen Y, Wang Z, Zhong Z (2019) $\mathrm{CO}_{2}$ emissions, economic growth, renewable and non-renewable energy production and foreign trade in China. Renewable Energy 131:208-216. https://doi.org/ 10.1016/j.renene.2018.07.047

Cheng C, Ren X, Dong K, Dong X, Wang Z (2021) How does technological innovation mitigate $\mathrm{CO}_{2}$ emissions in OECD countries? Heterogeneous analysis using panel quantile regression. J Environ Manage 280:111818. https://doi.org/10.1016/j.jenvman.2020.111818

Dauda L, Long X, Mensah CN, Salman M, Boamah KB, AmponWireko S, Kofi Dogbe CS (2021) Innovation, trade openness and $\mathrm{CO}_{2}$ emissions in selected countries in Africa. J Clean Prod 281:125143. https://doi.org/10.1016/j.jclepro.2020.125143

Demir C, Cergibozan R, Ari A (2020) Environmental dimension of innovation: time series evidence from Turkey. Environ Dev Sustain 22(3):2497-2516. https://doi.org/10.1007/ s10668-018-00305-0

Dogan E, Inglesi-Lotz R (2020) The impact of economic structure to the environmental Kuznets curve (EKC) hypothesis: evidence from European countries. Environ Sci Pollut Res 27(11):1271712724. https://doi.org/10.1007/s11356-020-07878-2

Fareed Z, Salem S, Adebayo TS, Pata UK, Shahzad F (2021) Role of export diversification and renewable energy on the load capacity factor in Indonesia: a fourier quantile causality approach. Front Environ Sci 9:434. https://doi.org/10.3389/fenvs.2021.770152

Gao J, Zhang L (2021) Does biomass energy consumption mitigate $\mathrm{CO}_{2}$ emissions? The role of economic growth and urbanization: evidence from developing Asia. Journal of the Asia Pacific Economy 26(1):96-115. https://doi.org/10.1080/13547860.2020.1717902

Grossman GM, Krueger AB (1991) Environmental impacts of a North American free trade agreement. In Papers (No. 158; Papers). Princeton, Woodrow Wilson School - Public and International Affairs. https://ideas.repec.org/p/fth/priwpu/158.html. Accessed 25 May 2021

Hanif I, Faraz Raza SM, Gago-de-Santos P, Abbas Q (2019) Fossil fuels, foreign direct investment, and economic growth have triggered $\mathrm{CO}_{2}$ emissions in emerging Asian economies: Some empirical evidence. Energy 171:493-501. https://doi.org/10.1016/j. energy.2019.01.011

Haseeb A, Xia E, Danish B, M. A., \& Abbas, K. (2018) Financial development, globalization, and $\mathrm{CO}_{2}$ emission in the presence of EKC: evidence from BRICS countries. Environ Sci Pollut Res 25(31):31283-31296. https://doi.org/10.1007/s11356-018-3034-7
He X, Adebayo TS, Kirikkaleli D, Umar M (2021) Consumption-based carbon emissions in Mexico: an analysis using the dual adjustment approach. Sustainable Production and Consumption 27:947-957. https://doi.org/10.1016/j.spc.2021.02.020

IEA (2021) International Energy Association. https://www.iea.org/ countries/sweden. Accessed 4 January 2021

Khan M, Ozturk I (2021) Examining the direct and indirect effects of financial development on $\mathrm{CO}_{2}$ emissions for 88 developing countries. J Environ Manage 293:112812. https://doi.org/10.1016/j. jenvman.2021.112812

Kihombo S, Ahmed Z, Chen S, Adebayo TS, Kirikkaleli D (2021) Linking financial development, economic growth, and ecological footprint: what is the role of technological innovation? Environ Sci Pollut Res. https://doi.org/10.1007/s11356-021-14993-1

Kirikkaleli D, and Adebayo TS (2020) Do renewable energy consumption and financial development matter for environmental sustainability? New global evidence. Sustainable Development, 2(4). https://doi.org/10.1002/sd.2159

Kirikkaleli D, Adebayo TS (2021) Do renewable energy consumption and financial development matter for environmental sustainability? New global evidence. Sustain Dev 29(4):583-594

Kirikkaleli D, Güngör H, Adebayo TS (2021) Consumption-based carbon emissions, renewable energy consumption, financial development and economic growth in Chile. Bus Strateg Environ 5(8):12-24

Ko Y-C, Zigan K, Liu Y-L (2021) Carbon capture and storage in South Africa: a technological innovation system with a political economy focus. Technol Forecast Soc Chang 166:120633. https://doi. org/10.1016/j.techfore.2021.120633

Koengkan M, Fuinhas JA, Santiago R (2020) Asymmetric impacts of globalisation on $\mathrm{CO}_{2}$ emissions of countries in Latin America and the Caribbean. Environment Systems and Decisions 40(1):135147. https://doi.org/10.1007/s10669-019-09752-0

Koondhar MA, Shahbaz M, Memon KA, Ozturk I, Kong R (2021) A visualization review analysis of the last two decades for environmental Kuznets curve "EKC" based on co-citation analysis theory and pathfinder network scaling algorithms. Environ Sci Pollut Res 28(13):16690-16706. https://doi.org/10.1007/ s11356-020-12199-5

Kraft J, Kraft A (1978) On the relationship between energy and GNP. The Journal of Energy and Development 3(2):401-403

Le HP, Ozturk I (2020) The impacts of globalization, financial development, government expenditures, and institutional quality on $\mathrm{CO}_{2}$ emissions in the presence of environmental Kuznets curve. Environ Sci Pollut Res 27(18):22680-22697. https://doi.org/10. 1007/s11356-020-08812-2

Leal PH, Marques AC (2021) The environmental impacts of globalisation and corruption: evidence from a set of African countries. Environ Sci Policy 115:116-124. https://doi.org/10.1016/j.envsci. 2020.10.013

Li J, Zhao Y, Zhang A, Song B, Hill RL (2021a) Effect of grazing exclusion on nitrous oxide emissions during freeze-thaw cycles in a typical steppe of Inner Mongolia. Agr Ecosyst Environ 307:107217. https://doi.org/10.1016/j.agee.2020.107217

Li X, Zhang C, Zhang B, Wu D, Shi Y, Zhang W, Ye Q, Yan J, Fu J, Fang C, Ha D, Fu S (2021b) Canopy and understory nitrogen addition have different effects on fine root dynamics in a temperate forest: implications for soil carbon storage. New Phytol 231(4):1377-1386. https://doi.org/10.1111/nph.17460

Li X, Zhang C, Zhang B, Wu D, Zhu D, Zhang W, Ye Q, Yan J, Fu J, Fang C, Ha D, Fu S (2021c) Nitrogen deposition and increased precipitation interact to affect fine root production and biomass in a temperate forest: implications for carbon cycling. Sci Total Environ 765:144497. https://doi.org/10.1016/j.scitotenv.2020.144497 
Lin X, Zhao Y, Ahmad M, Ahmed Z, Rjoub H, Adebayo TS (2021) Linking innovative human capital, economic growth, and $\mathrm{CO}_{2}$ emissions: an empirical study based on Chinese Provincial Panel Data. Int J Environ Res Public Health 18(16):8503. https://doi. org/10.3390/ijerph18168503

Liu SMA, Jiang Y, Wu H, Ahmed Z, Ullah I (2021) Linking green human resource practices and environmental economics performance: the role of green economic organizational culture and green psychological climate. Int J Environ Res Public Health 18(20):10953. https://doi.org/10.3390/ijerph182010953

Miao R, Qiu X, Guo M, Musa A, Jiang D (2018) Accuracy of spacefor-time substitution for vegetation state prediction following shrub restoration. Journal of Plant Ecology 11(2):208-217. https://doi.org/10.1093/jpe/rtw133

Mikayilov JI, Galeotti M, Hasanov FJ (2018) The impact of economic growth on $\mathrm{CO}_{2}$ emissions in Azerbaijan. J Clean Prod 197:15581572. https://doi.org/10.1016/j.jclepro.2018.06.269

Muhammad B (2019) Energy consumption, $\mathrm{CO}_{2}$ emissions and economic growth in developed, emerging and Middle East and North Africa countries. Energy 179:232-245. https://doi.org/10.1016/j. energy.2019.03.126

Muhammad F, Khan A (2021) Influence of tourism, governance, and foreign direct investment on energy consumption and $\mathrm{CO}_{2}$ emissions: a panel analysis of Muslim countries. Environ Sci Pollut Res 28(1):416-431

Munir Q, Lean $\mathrm{HH}$, Smyth R (2020) $\mathrm{CO}_{2}$ emissions, energy consumption and economic growth in the ASEAN-5 countries: a crosssectional dependence approach. Energy Economics 85:104571. https://doi.org/10.1016/j.eneco.2019.104571

Oladipupo SD, Adeshola I, Adebayo TS, Rjoub H (2021) Wavelet analysis of impact of renewable energy consumption and technological innovation on $\mathrm{CO}_{2}$ emissions: evidence from Portugal. Environ Sci Pollut Res 1-18

Ozturk I, Acaravci A (2016) Energy consumption, $\mathrm{CO}_{2}$ emissions, economic growth, and foreign trade relationship in Cyprus and Malta. Energy Sources Part B 11(4):321-327. https://doi.org/10. 1080/15567249.2011.617353

Panayotou T (1997) Demystifying the environmental Kuznets curve: turning a black box into a policy tool. Environ Dev Econ 2(4):465-484. https://doi.org/10.1017/S1355770X97000259

Rahman MM (2020) Environmental degradation: the role of electricity consumption, economic growth and globalisation. J Environ Manage 253:109742. https://doi.org/10.1016/j.jenvman.2019.109742

Salari M, Javid RJ, Noghanibehambari H (2021) The nexus between $\mathrm{CO}_{2}$ emissions, energy consumption, and economic growth in the U.S. Economic Analysis and Policy 69:182-194. https://doi.org/ 10.1016/j.eap.2020.12.007

Sarkodie SA, Strezov V (2019) Effect of foreign direct investments, economic development and energy consumption on greenhouse gas emissions in developing countries. Sci Total Environ 646:862-871. https://doi.org/10.1016/j.scitotenv.2018.07.365

Shahbaz M, Khan S, Ali A, Bhattacharya M (2017) The impact of globalization on $\mathrm{CO}_{2}$ emissions in china. The Singapore Economic Review 62(04):929-957. https://doi.org/10.1142/S021759081 7400331

Shahbaz M, Shahzad SJH, Mahalik MK, Hammoudeh S (2018) Does globalisation worsen environmental quality in developed economies? Environ Model Assess 23(2):141-156. https://doi.org/10. 1007/s10666-017-9574-2

Shahbaz M, Sharma R, Sinha A, Jiao Z (2021) Analyzing nonlinear impact of economic growth drivers on $\mathrm{CO}_{2}$ emissions: designing an SDG framework for India. Energy Policy 148:111965. https:// doi.org/10.1016/j.enpol.2020.111965

Shan S, Ahmad M, Tan Z, Adebayo TS, Man Li RY, Kirikkaleli D (2021) The role of energy prices and non-linear fiscal decentralization in limiting carbon emissions: tracking environmental sustainability. Energy 234:121243. https://doi.org/10.1016/j. energy.2021.121243

Shin Y, Yu B, Greenwood-Nimmo M (2014) Modelling asymmetric cointegration and dynamic multipliers in a nonlinear ARDL framework. In R. C. Sickles \& W. C. Horrace (Eds.), Festschrift in Honor of Peter Schmidt: Econometric Methods and Applications (pp. 281-314). Springer. https://doi.org/10.1007/ 978-1-4899-8008-3_9

Solarin SA, Al-Mulali U, Musah I, Ozturk I (2017) Investigating the pollution haven hypothesis in Ghana: an empirical investigation. Energy 124:706-719. https://doi.org/10.1016/j.energy.2017.02. 089

Su C-W, Xie Y, Shahab S, Faisal CMN, Hafeez M, Qamri GM (2021a) Towards achieving sustainable development: role of technology innovation, technology adoption and $\mathrm{CO}_{2}$ emission for BRICS. Int J Environ Res Public Health 18(1):277. https://doi.org/10.3390/ ijerph18010277

Su Z-W, Umar M, Kirikkaleli D, Adebayo TS (2021b) Role of political risk to achieve carbon neutrality: evidence from Brazil. J Environ Manage 298:113463. https://doi.org/10.1016/j.jenvman.2021.113463

Udemba EN, Yalçıntaş S (2021) Interacting force of foreign direct invest (FDI), natural resource and economic growth in determining environmental performance: a nonlinear autoregressive distributed lag (NARDL) approach. Resour Policy 73:102168. https://doi.org/10.1016/j.resourpol.2021.102168

Udemba EN, Adebayo TS, Ahmed Z, Kirikkaleli D (2021a) Determinants of consumption-based carbon emissions in Chile: an application of non-linear ARDL. Environ Sci Pollut Res. https://doi. org/10.1007/s11356-021-13830-9

Udemba EN, Güngör H, Bekun FV, Kirikkaleli D (2021b) Economic performance of India amidst high $\mathrm{CO}_{2}$ emissions. Sustainable Production and Consumption 27:52-60. https://doi.org/10.1016/j.spc. 2020.10.024

Usman O, Iortile IB, Ike GN (2020) Enhancing sustainable electricity consumption in a large ecological reserve-based country: the role of democracy, ecological footprint, economic growth, and globalisation in Brazil. Environ Sci Pollut Res 27(12):13370-13383. https://doi.org/10.1007/s11356-020-07815-3

World Bank (2021) World Development Indicators. http://data.world bank.org/country/sweden

Xu Z, Baloch MA, Danish M, F., Zhang, J., \& Mahmood, Z. (2018) Nexus between financial development and $\mathrm{CO}_{2}$ emissions in Saudi Arabia: analyzing the role of globalization. Environ Sci Pollut Res 25(28):28378-28390. https://doi.org/10.1007/s11356-018-2876-3

Yameogo CEW, Omojolaibi JA, Dauda ROS (2021) Economic globalisation, institutions and environmental quality in Sub-Saharan Africa. Research in Globalization 3:100035. https://doi.org/10. 1016/j.resglo.2020.100035

Zaidi SAH, Zafar MW, Shahbaz M, Hou F (2019) Dynamic linkages between globalization, financial development and carbon emissions: evidence from Asia Pacific Economic Cooperation countries. J Clean Prod 228:533-543. https://doi.org/10.1016/j.jclep ro.2019.04.210

Zhao J, Shahbaz M, Dong X, Dong K (2021) How does financial risk affect global $\mathrm{CO}_{2}$ emissions? The role of technological innovation. Technol Forecast Soc Chang 168:120751. https://doi.org/10. 1016/j.techfore.2021.120751

Zivot E, Andrews DWK (2002) Further evidence on the great crash, the oil-price shock, and the unit-root hypothesis. Journal of Business \& Economic Statistics 20(1):25-44. https://doi.org/10.1198/ 073500102753410372

Publisher's Note Springer Nature remains neutral with regard to jurisdictional claims in published maps and institutional affiliations. 